\title{
THE
}

\section{Modeling the impact of declining sea ice on the Arctic marine planktonic ecosystem}

Jinlun Zhang

Yvette H. Spitz

Michael Steele

Carin Ashjian

Robert Campbell

University of Rhode Island, rgcampbell@uri.edu

See next page for additional authors

Follow this and additional works at: https://digitalcommons.uri.edu/gsofacpubs

Terms of Use

All rights reserved under copyright.

\section{Citation/Publisher Attribution}

Zhang, J., Y. H. Spitz, M. Steele, C. Ashjian, R. Campbell, L. Berline, and P. Matrai (2010), Modeling the impact of declining sea ice on the Arctic marine planktonic ecosystem, J. Geophys. Res., 115, C10015, doi: 10.1029/2009JC005387.

Available at: https://doi.org/10.1029/2009JC005387

This Article is brought to you for free and open access by the Graduate School of Oceanography at DigitalCommons@URI. It has been accepted for inclusion in Graduate School of Oceanography Faculty Publications by an authorized administrator of DigitalCommons@URI. For more information, please contact digitalcommons-group@uri.edu. 


\section{Authors}

Jinlun Zhang, Yvette H. Spitz, Michael Steele, Carin Ashjian, Robert Campbell, Léo Berline, and Patricia Matrai

This article is available at DigitalCommons@URI: https://digitalcommons.uri.edu/gsofacpubs/488 


\title{
Modeling the impact of declining sea ice on the Arctic marine planktonic ecosystem
}

\author{
Jinlun Zhang, ${ }^{1}$ Yvette H. Spitz, ${ }^{2}$ Michael Steele, ${ }^{1}$ Carin Ashjian, ${ }^{3}$ Robert Campbell, ${ }^{4}$ \\ Léo Berline, ${ }^{5}$ and Patricia Matrai ${ }^{6}$ \\ Received 16 March 2009; revised 3 May 2010; accepted 10 June 2010; published 8 October 2010.
}

[1] We have developed a coupled 3-D pan-Arctic biology/sea ice/ocean model to investigate the impact of declining Arctic sea ice on the marine planktonic ecosystem over 1988-2007. The biophysical model results agree with satellite observations of a generally downward trend in summer sea ice extent during 1988-2007, resulting in an increase in the simulated photosynthetically active radiation (PAR) at the ocean surface and marine primary productivity (PP) in the upper $100 \mathrm{~m}$ over open water areas of the Arctic Ocean. The simulated Arctic sea ice thickness has decreased steadily during 1988-2007, leading to an increase in PAR and PP in sea ice-covered areas. The simulated total PAR in all areas of the Arctic Ocean has increased by 43\%, from 146 TW in 1988 to 209 TW in 2007; the corresponding total PP has increased by $50 \%$, from $456 \mathrm{Tg} \mathrm{C} \mathrm{yr}^{-1}$ in 1988 to $682 \mathrm{Tg} \mathrm{C} \mathrm{yr}^{-1}$ in 2007. The simulated PAR and PP increases mainly occur in the seasonally and permanently ice-covered Arctic Ocean. In addition to increasing PAR, the decline in sea ice tends to increase the nutrient availability in the euphotic zone by enhancing air-sea momentum transfer, leading to strengthened upwelling and mixing in the water column and therefore increased nutrient input into the upper ocean layers from below. The increasing nutrient availability also contributes to the increase in the simulated PP, even though significant surface nutrient drawdown in summer is simulated. In conjunction with increasing surface absorption of solar radiation and rising surface air temperature, the increasing surface water temperature in the Arctic Ocean peripheral seas further contributes to the increase in PP. As PP has increased, so has the simulated biomass of phytoplankton and zooplankton.

Citation: Zhang, J., Y. H. Spitz, M. Steele, C. Ashjian, R. Campbell, L. Berline, and P. Matrai (2010), Modeling the impact of declining sea ice on the Arctic marine planktonic ecosystem, J. Geophys. Res., 115, C10015, doi:10.1029/2009JC005387.

\section{Introduction}

[2] A significant decline of arctic sea ice has been observed in recent years. The decline was particularly dramatic during summer 2007, when most of the Pacific sector of the Arctic Ocean was ice free and the total Arctic sea ice extent plunged to the lowest level since satellite observations began in the 1970s [Kerr, 2007; Stroeve et al., 2008; Comiso et al., 2008]. This dramatic decline occurred after years of shrinking and thinning of the ice cover [e.g., Meier et al., 2007; Nghiem et al., 2007; Rothrock et al., 1999, 2008; Lindsay et al., 2009],

\footnotetext{
${ }^{1}$ University of Washington, Seattle, Washington, USA

${ }^{2}$ Oregon State University, Corvallis, Oregon, USA.

${ }^{3}$ Woods Hole Oceanographic Institution, Woods Hole, Massachusetts, USA.

${ }^{4}$ University of Rhode Island, Kingston, Rhode Island, USA.

${ }^{5}$ Laboratoire d'Océanographie de Villefranche, Villefranche-sur-Mer, France.

${ }^{6}$ Bigelow Laboratory for Ocean Sciences, West Boothbay Harbor, Maine, USA.

Copyright 2010 by the American Geophysical Union. 0148-0227/10/2009JC005387
}

linked to an increase in surface air temperature (SAT) and changes in wind circulation [Hassol, 2004; Serreze et al., 2007]. The ice cover has been shrinking in every season and in every region, creating longer melt seasons [Belchansky et al., 2004; Stroeve et al., 2006] and longer periods of icefree water on the shelves and even extending into the central basins. Perennial ice has been rapidly replaced in recent years by thinner first-year ice [Nghiem et al., 2007; Kwok, 2007; Maslanik et al., 2007] that is more sensitive to changes in atmospheric and oceanic forcing [Zhang et al., 2008]. The retreat of sea ice has increased the surface absorption of solar radiation in summer because of the positive ice-albedo feedback [Perovich et al., 2007; 2008], leading to warmer surface waters [Steele et al., 2008].

[3] The decline of Arctic sea ice may have a profound effect on the marine ecosystem [Study of Environmental Arctic Change, Science Steering Committee (SEARCH SSC), 2001; Hassol, 2004]. Despite the presence of the ice cover and extreme polar conditions, the Arctic shelf seas are ranked among the most productive in the world [Gosselin et al., 1997; Hill and Cota, 2005]. By comparison the central Arctic basin has one of the lowest annual primary productivity 
(PP) rates of the world's oceans [Cota et al., 1996; Wheeler et al., 1997]. However, field measurements in the early 1990s [Wheeler et al., 1996; Wheeler, 1997] found that PP was higher than previously reported in the central Arctic and that the region supports an active biological community that contributes to the organic carbon and nitrogen cycling. In regions with ice cover of $50 \%-90 \%$, diatoms may dominate phytoplankton biomass, whereas under thicker ice, picoplankton often are more abundant [Booth and Horner, 1997; Gosselin et al., 1997]. Ice algae contribute on average $57 \%$ of the combined water column and sea ice primary production in the central Arctic and 3\% in the shelf regions [Gosselin et al., 1997; Sakshaug, 2004]; their importance relies more on the timing of their production peak (1-2 months before the pelagic bloom) than on the magnitude of their PP maximum [Carmack and Wassmann, 2006].

[4] Seasonal production cycles in the Arctic Ocean are characterized by a single high-amplitude peak in plant biomass followed with a long delay by a single lesser peak in zooplankton biomass [Cushing, 1959]. Zooplankton biomass in the Arctic is generally dominated by large copepods of the genus Calanus [e.g., Thibault et al., 1999; Arashkevich et al., 2002; Ashjian et al., 2003; Campbell et al., 2009]. These large-bodied copepods overwinter at depth with their ascent in spring timed to take advantage of the spring bloom for reproduction and growth. The life cycles of these copepods are very long compared to those at lower latitudes because of the shorter growing season and slower growth rates at low temperatures. This combination of life cycle strategy and slow growth at low temperatures results in the long delay between peaks in plant and grazer biomass. Because of low grazer biomass at the onset of the spring bloom, much of the spring production may not be consumed in the water column. For example, in the Chukchi and Beaufort seas mesozooplankton and microzooplankton grazing combined consumed only $44 \%$ of the water column PP, leaving more than half available for local export to the benthos or offshore transport into the adjacent basin [Campbell et al., 2009; Sherr et al., 2009]. An exception is the Barents Sea that is a pelagic dominated system where zooplankton advected from the Norwegian Sea can significantly augment the biomass, and abundant commercially important pelagic fish species are found [e.g., Arashkevich et al., 2002; Bluhm and Gradinger, 2008].

[5] Variability and change in the extent, thickness, timing of annual retreat from the Arctic periphery, and duration of the Arctic ice cover will have a major impact on ecosystem functioning and biogeochemical cycling [e.g., Sakshaug and Slagstad, 1992; Walsh et al., 2004]. Light, temperature, and nutrients govern the variability of the primary productivity in the Arctic Ocean [Andersen, 1989; Smith and Sakshaug, 1990; Gosselin et al., 1997; Hill and Cota, 2005; Lee and Whitledge, 2005]. Changes in the ice cover affect the penetration of light into the water column, mixing due to wind stirring and buoyancy flux at the ocean surface, the oceanic mixed layer temperature, and upwelling and shelf-basin exchange of nutrients. Upwelling is often facilitated at the ice edge while suppressed beneath pack ice [e.g., Mundy et al., 2009]. The timing of the spring bloom depends on ice/snowmelt, when the increase in light and freshwater enhances ocean stratification and provides conditions for growth. The magnitude of the spring bloom is limited by the initial nutrient load; this is set by the depths of the surface mixed layer and of winter mixing that control nutrient availability [Sambrotto et al., 1986; Wassmann et al., 1996]. In the postbloom nutrient limited environment, PP is controlled by the depth of the mixed layer, vertical mixing of nutrients from below the pycnocline, and horizontal advection of nutrients [Reigstad et al., 2002].

[6] Intuitively, the decline of Arctic sea ice will increase primary production and support a richer ecosystem through enhanced wind-driven mixing and light penetration as long as nutrients do not become limiting and the compensation depth is not regularly exceeded. This is more likely over the vast shelf regions, which constitute $30 \%$ of the area of the Arctic Ocean [e.g., Grebmeier and Barry, 1991] and presently are experiencing loss of summer ice earlier than other Arctic regions as predicted by global climate models [Hassol, 2004] and observed by satellite remote sensing over the past decade [e.g., Stroeve et al., 2008]. Shelf regions may begin to resemble "sub-Arctic" regions that are warmer and generally have a greater biological productivity, such as the Bering Sea. Indeed, Pabi et al. [2008] and Arrigo et al. [2008] report a generally increasing trend in pan-Arctic marine PP over 1998-2007 based on satellite observations integrated in the upper $100 \mathrm{~m}$ over mainly open water areas, whereas Moline et al. [2008] report a significant increase in chlorophyll $a$ in 2007 compared to previous years. The PP increase is significantly correlated with the decrease in sea ice or increase in open water in mainly the seasonally ice-covered shelf regions of the Pacific sector [Pabi et al., 2008]. In most of the central Arctic, with a nearly permanent ice cover, biological productivity may also be enhanced because the thinning ice and snow cover tends to allow more light to penetrate into the water column, though a shallow, stable mixed layer may inhibit nutrient replenishment and keep PP low.

[7] In this study, we seek to address questions including: To what degree does the thinning ice cover enhance biological productivity in the permanently ice-covered central Arctic? To what degree does the enhanced PP in the seasonally ice-covered areas in the Arctic Ocean, as reported by Pabi et al. [2008] and Arrigo et al. [2008], boost the standing stocks of consumers of primary production there? And more generally, what is the impact of declining sea ice on the Arctic marine planktonic ecosystem as a whole? The answers to these questions are explored here through numerical modeling.

[8] Model studies of the Arctic marine planktonic ecosystem are complicated by the fact that the Arctic contains one of the least studied marine ecosystems in the world. For example, despite recent advances in understanding through field programs such as the NSF Shelf-Basin Interactions (SBI) Program [Grebmeier and Harvey, 2005], NOAA's Ocean Exploration, Canada's Arctic Shelf Exchange Study (CASES), and Norway's Carbon Flux and Ecosystem Feedback in the Northern Barents Sea, little is known regarding standing stocks and processes during the winter. Although some of the biological studies, such as those conducted during the Surface Heat Budget of the Arctic Ocean (SHEBA) program during 1997-1998 [Uttal et al., 2002] or CASES, provide valuable information about the annual cycle of sea ice, nutrients, phytoplankton, microzooplankton, and mesozooplankton [e.g., Melnikov et al., 2002; Ashjian et al., 2003; Sherr et al., 2003], few biological rates were measured in these studies. Additional difficulties in modeling 
studies are associated with the possibly different ecosystem characteristics and functioning over various shelf and basin regions in the Arctic Ocean [Carmack et al., 2006].

[9] Despite the difficulties, numerical pelagic biological models have been used successfully to study the planktonic ecosystem for various regions of the Arctic Ocean [e.g., Slagstad and Stole-Hansen, 1991; Lebedeva et al., 1995; Wassmann et al., 2006; Jin et al., 2006; Ellingsen et al., 2008; Lavoie et al., 2009]. In particular, Walsh and Dieterle [1994] studied $\mathrm{CO}_{2}$ cycling in the Chukchi Sea by successfully adapting a pelagic biological model developed for the southeastern Bering Sea. The model was further used for more extensive studies of the biogeochemical processes of the Chukchi and Beaufort seas [Walsh et al., 1997, 2004, 2005]. Pelagic biological models have also been used successfully for the ice-covered Southern Ocean [e.g., Arrigo et al., 1993, 2003; Lancelot et al., 2000; Hannon et al., 2001; Fennel et al., 2003]. These polar biological models vary in complexity. Many of them are 1-D models, and few are explicitly coupled to a sea ice model. Nevertheless, these models have yielded considerable insights about the functioning of ecosystems in the ice-covered polar oceans. A number of more complex, global, pelagic, biological models have been coupled explicitly to sea ice models, and they were able to capture some of the basic features of the arctic biogeochemical properties in spite of relatively crude model resolutions [e.g., Aumont et al., 2003; Schmittner et al., 2005].

[10] Here we have developed a fully coupled 3-D panArctic biology/sea ice/ocean model and used the model to hindcast the physical (ocean, sea ice) conditions and marine planktonic ecosystem and, using those hindcasts, to investigate the impact of the ongoing decline in sea ice on the marine planktonic ecosystem in the Arctic Ocean over the past two decades. Hindcasts are compared to available field data in three different regions to validate and better understand the model. We mainly focus on the linkages between the changes in the planktonic ecosystem, sea ice, and light and nutrient availability.

\section{Model Description}

[11] The coupled biophysical model consists of three model elements: a sea ice model, an ocean circulation model, and a pelagic biological model. The basic coupling of the model elements is as follows. The sea ice model is driven by atmospheric forcing. Then, the ice model supplies surface heat, salt (or freshwater), and momentum fluxes, together with the input of river runoff of freshwater, to the ocean model as ocean surface or lateral boundary conditions. By calculating ice thickness, snow depth, and surface albedo, the ice model also determines net shortwave radiation at the ocean surface, which is supplied to the planktonic ecosystem model and converted to photosynthetically active radiation (PAR). In turn, the ocean model supplies current and heatexchange information to the ice model. The ocean model also computes the advection, diffusion, and mixing of the state variables of the biological model.

\subsection{Sea Ice and Ocean Circulation Models}

[12] The sea ice model is a dynamic-thermodynamic model based on the studies by Hibler [1979] and Zhang and Hibler
[1997] and adapted to parallel computing following Zhang and Rothrock [2003]. The model employs a teardrop viscous-plastic ice rheology that determines the relationship between ice internal stress and ice deformation [Zhang and Rothrock, 2005] and an efficient numerical method to solve the ice momentum equation [Zhang and Hibler, 1997]. Embedded into the sea ice model is a snow model following Zhang et al. [1998]. The sea ice model uses National Centers for Environmental Prediction/National Center for Atmospheric Research (NCEP/NCAR) reanalysis [Kalnay et al., 1996; ftp.cdc.noaa] downwelling shortwave radiation to determine the net shortwave radiation at the ocean surface for both open water and ice-covered areas. The net shortwave radiation at the ocean surface depends on surface albedo and transmittance through sea ice and is calculated following Maykut and Untersteiner [1971] and Hibler [1980].

[13] The ocean circulation model is based on the Parallel Ocean Program (POP) developed at Los Alamos National Laboratory. The POP model is a Brya-Cox-Semtner-type ocean model [Bryan, 1969; Cox, 1984; Semtner, 1986] with numerous improvements, including an implicit free surface formulation of the barotropic mode and model adaptation to parallel computing [e.g., Smith et al., 1992; Dukowicz and Smith, 1994]. The magnitude of ocean vertical mixing in the model is adjusted based on observations in the Arctic Ocean. Vertical mixing is calculated by the nonlocal K-profile parameterization (KPP) scheme [Large et al., 1994]. With the KPP mixing scheme, mixing in the surface mixed layer is determined by turbulent processes parameterized by a bulk Richardson number, and mixing in the interior (below the mixed layer) is governed by shear instability and internal wave activity and parameterized by a "background" diffusivity. Given these observations, D'Asaro and Morison [1992] report that the diffusivity value in the ice-covered deep arctic waters is order of magnitude $10^{-6} \mathrm{~m}^{2} \mathrm{~s}^{-1}$, much smaller than that in the ice-free oceans. Parameterizing the background diffusivity based on this value significantly improves the simulation of vertical mixing both in the surface waters and in the interior and therefore the simulation of ocean temperature and salinity in the Arctic Ocean as compared to observations [Zhang and Steele, 2007]. Such improvement is important for this study because realistic simulation of mixing and temperature and salinity structure in the upper ocean is necessary to produce realistic entrainment of nutrients into the upper layer and planktonic growth rates.

\subsection{Biological Model}

[14] The biological model is a modified version of the Kishi et al. [2007] 11-component lower-trophic model adapted to the Arctic Ocean. With nitrogen as model currency, the Kishi et al. ecosystem model incorporates two phytoplankton components (large phytoplankton, PL; small phytoplankton, PS), three zooplankton components (microzooplankton, ZS; mesozooplankton/copepods, ZL; predator zooplankton, ZP), dissolved organic nitrogen, detrital particulate organic nitrogen, particulate organic silica, nitrate, ammonium, and silicate. Sea ice algae are not incorporated into the ecosystem model. In our model, we redefine the two phytoplankton components to more accurately reflect the Arctic Ocean ecosystem dynamics. In the Kishi et al. [2007] model, silicate is a limiting nutrient for PL but not PS. Therefore, by definition, this component is required to be composed of diatoms only, 
Table 1. Values and Units for Parameters Used in the Biological Model ${ }^{\mathrm{a}}$

\begin{tabular}{|c|c|c|c|}
\hline PARfrac & Fraction of shortwave radiation that is photosynthetically active & nondim & 0.43 \\
\hline$\alpha_{1}$ & Light attenuation due to seawater & $\mathrm{m}^{-1}$ & 0.04 \\
\hline$\alpha_{\mathrm{S} /} \alpha_{\mathrm{L}}$ & Light attenuation due PS/PL & $\mathrm{m}^{2}(\mathrm{mmol} \mathrm{N})^{-1}$ & 0.04 \\
\hline AlphaPS/AlphaPL & PS/PL photochemical reaction coefficient & $\mathrm{m}^{2} \mathrm{~W}^{-1} \mathrm{~d}^{-1}$ & 0.025 \\
\hline BetaPS/BetaPL & PS/PL photoinhibition coefficient & $\mathrm{m}^{2} \mathrm{~W}^{-1} \mathrm{~d}^{-1}$ & 0.00023 \\
\hline$V_{\max } / V_{\max } \mathrm{L}$ & $\mathrm{PS} / \mathrm{PL}$ maximum photosynthetic rate at $0^{\circ} \mathrm{C}$ & $d^{-1}$ & $0.7 / 2.0$ \\
\hline$K_{\mathrm{NO} 3 \mathrm{~S} /} K_{\mathrm{NO} 3 \mathrm{~L}}$ & PS/PL half saturation constant for nitrate & $\mathrm{mmol} \mathrm{N} \mathrm{m}{ }^{-3}$ & 0.7 \\
\hline$K_{\mathrm{NH} 4 \mathrm{~S}} / \mathrm{K}_{\mathrm{NH} 4 \mathrm{~L}}$ & PS/PL half saturation constant for ammonium & $\mathrm{mmol} \mathrm{N} \mathrm{m}{ }^{-3}$ & 0.2 \\
\hline $\mathrm{K}_{\mathrm{SiL}}$ & PL half saturation constant for silicate & $\mathrm{mmol} \mathrm{Si} \mathrm{m}^{-3}$ & 1.15 \\
\hline$\psi_{\mathrm{S}} / \psi_{\mathrm{L}}$ & PS/PL ammonium inhibition coefficient & $\mathrm{m}^{3}(\mathrm{mmol} \mathrm{N})^{-1}$ & 1.0 \\
\hline $\mathrm{K}_{\mathrm{GppS}} / \mathrm{K}_{\mathrm{GppL}}$ & PS/PL temperature coefficient for photosynthetic rate & ${ }^{\circ} \mathrm{C}^{-1}$ & 0.0693 \\
\hline $\operatorname{Re}_{\mathrm{SPSO} O} / \operatorname{ReS}_{\mathrm{PL} 0}$ & $\mathrm{PS} / \mathrm{PL}$ respiration rate at $0^{\circ} \mathrm{C}$ & $d^{-1}$ & 0.03 \\
\hline$K_{\mathrm{ResPS}} / K_{\mathrm{ReSPL}}$ & PS/PL temperature coefficient for respiration & ${ }^{\circ} \mathrm{C}^{-1}$ & 0.0519 \\
\hline$\gamma_{\mathrm{S}} / \gamma_{\mathrm{L}}$ & PS/PL ratio of extracellular excretion to photosynthesis & nondim & 0.135 \\
\hline Mor ${ }_{\mathrm{PS} 0}$ & PS mortality rate at $0^{\circ} \mathrm{C}$ & $\mathrm{m}^{3}(\mathrm{mmol} \mathrm{N})^{-1} \mathrm{~d}^{-1}$ & 0.0585 \\
\hline Mor $_{\text {PL0 }}$ & $\mathrm{PL}$ mortality rate at $0^{\circ} \mathrm{C}$ & $\mathrm{m}^{3}(\mathrm{mmol} \mathrm{N})^{-1} \mathrm{~d}^{-1}$ & 0.0290 \\
\hline$K_{\mathrm{MorPS}} / K_{\mathrm{MorPL}}$ & PS/PL temperature coefficient for mortality & ${ }^{\circ} \mathrm{C}^{-1}$ & 0.0693 \\
\hline $\mathrm{GR}_{\operatorname{maxSps}}$ & Maximum grazing rate at $0^{\circ} \mathrm{C}, \mathrm{ZS}$ on PS & $d^{-1}$ & 0.50 \\
\hline $\mathrm{GR}_{\operatorname{maxSpl}} \mathrm{b}$ & Maximum grazing rate at $0^{\circ} \mathrm{C}, \mathrm{ZS}$ on $\mathrm{PL}$ & $d^{-1}$ & 0.20 \\
\hline $\mathrm{GR}_{\operatorname{maxLps}}$ & Maximum grazing rate at $0^{\circ} \mathrm{C}, \mathrm{ZL}$ on PS & $d^{-1}$ & 0.20 \\
\hline $\mathrm{GR}_{\operatorname{maxLpl}}$ & Maximum grazing rate at $0^{\circ} \mathrm{C}, \mathrm{ZL}$ on $\mathrm{PL}$ & $d^{-1}$ & 0.25 \\
\hline $\mathrm{GR}_{\operatorname{maxLzs}}$ & Maximum grazing rate at $0^{\circ} \mathrm{C}, \mathrm{ZL}$ on $\mathrm{ZS}$ & $d^{-1}$ & 0.45 \\
\hline $\mathrm{GR}_{\operatorname{maxPpl}}$ & Maximum grazing rate at $0^{\circ} \mathrm{C}, \mathrm{ZP}$ on $\mathrm{PL}$ & $d^{-1}$ & 0.10 \\
\hline $\mathrm{GR}_{\operatorname{maxPzs}}$ & Maximum grazing rate at $0^{\circ} \mathrm{C}, \mathrm{ZP}$ on $\mathrm{ZS}$ & $d^{-1}$ & 0.05 \\
\hline $\mathrm{GR}_{\operatorname{maxPzl}}$ & Maximum grazing rate at $0^{\circ} \mathrm{C}, \mathrm{ZP}$ on $\mathrm{ZL}$ & $d^{-1}$ & 0.10 \\
\hline$K_{\mathrm{GraS}} / K_{\mathrm{GraL}} / K_{\mathrm{GraP}}$ & $\mathrm{ZS} / \mathrm{ZL} / \mathrm{ZP}$ temperature coefficient for grazing & ${ }^{\circ} \mathrm{C}^{-1}$ & 0.0693 \\
\hline$\lambda_{\mathrm{S}} / \lambda_{\mathrm{L}} / \lambda_{\mathrm{P}}$ & ZS/ZL/ZP Ivlev constant & $\mathrm{m}^{3}(\mathrm{mmol} \mathrm{N})^{-1}$ & 1.4 \\
\hline PS2ZS*/PL2ZS*b & Threshold value for grazing, $\mathrm{ZS}$ on PS/PL & $\mathrm{mmol} \mathrm{N} \mathrm{m}^{-3}$ & 0.043 \\
\hline PS2ZL*/PL2ZL* & Threshold value for grazing, $\mathrm{ZL}$ on PS/PL & $\mathrm{mmol} \mathrm{N} \mathrm{m}^{-3}$ & 0.040 \\
\hline ZS2ZL* & Threshold value for grazing, ZL on ZS & $\mathrm{mmol} \mathrm{N} \mathrm{m}{ }^{-3}$ & 0.040 \\
\hline PL2ZP* & Threshold value for grazing, ZP on PL & $\mathrm{mmol} \mathrm{N} \mathrm{m}{ }^{-3}$ & 0.040 \\
\hline ZS2ZP*/ZL2ZP* & Threshold value for grazing, $\mathrm{ZP}$ on $\mathrm{ZS} / \mathrm{ZL}$ & $\mathrm{mmol} \mathrm{N} \mathrm{m}^{-3}$ & 0.040 \\
\hline$\psi \mathrm{PL}$ & Inhibition coefficient for $\mathrm{ZP}$ grazing on $\mathrm{PL}$ & $\mathrm{m}^{3}(\mathrm{mmol} \mathrm{N})^{-1}$ & 4.605 \\
\hline$\psi \mathrm{ZS}$ & Inhibition coefficient for $\mathrm{ZP}$ grazing on $\mathrm{ZS}$ & $\mathrm{m}^{3}(\mathrm{mmol} \mathrm{N})^{-1}$ & 3.010 \\
\hline $\mathrm{Mor}_{\mathrm{ZS} 0} / \mathrm{Mor}_{\mathrm{ZL} 0} / \mathrm{Mor}_{\mathrm{ZP0}}$ & $\mathrm{ZS} / \mathrm{ZL} / \mathrm{ZP}$ mortality rate at $0^{\circ} \mathrm{C}$ & $\mathrm{m}^{3}(\mathrm{mmol} \mathrm{N})^{-1} \mathrm{~d}^{-1}$ & 0.0585 \\
\hline$K_{\mathrm{MorZS}} / K_{\mathrm{MorZL}} / K_{\mathrm{MorZP}}$ & ZS/ZL/ZP temperature coefficient for mortality & ${ }^{\circ} \mathrm{C}^{-1}$ & 0.0693 \\
\hline$\alpha_{Z S} / \alpha_{Z L} / \alpha_{Z P}$ & ZS/ZL/ZP assimilation efficiency & nondim & 0.75 \\
\hline$\beta_{Z S} / \beta_{Z L} / \beta_{Z P}$ & ZS/ZL/ZP growth efficiency & nondim & 0.35 \\
\hline $\mathrm{Nit}_{0}$ & $\mathrm{NH} 4$ nitrification rate at $0^{\circ} \mathrm{C}$ & $d^{-1}$ & 0.03 \\
\hline $\mathrm{VP} 2 \mathrm{~N}_{0} / \mathrm{VP} 2 \mathrm{D}_{0}$ & Decomposition rates at $0^{\circ} \mathrm{C}, \mathrm{PON}$ to $\mathrm{NH} 4 / \mathrm{DON}$ & $d^{-1}$ & 0.10 \\
\hline VD2 $\mathrm{N}_{0}$ & Decomposition rates at $0^{\circ} \mathrm{C}, \mathrm{DON}$ to $\mathrm{NH} 4$ & $d^{-1}$ & 0.20 \\
\hline $\mathrm{VO}_{2} \mathrm{~S}_{0}$ & Decomposition rates at $0^{\circ} \mathrm{C}$, Opal to silicate & $d^{-1}$ & 0.10 \\
\hline$K_{\mathrm{Nit}}$ & Temperature coefficients for decomposition, $\mathrm{NH} 4$ nitrification & ${ }^{\circ} \mathrm{C}^{-1}$ & 0.0693 \\
\hline$K_{\mathrm{P} 2 \mathrm{D}} / K_{\mathrm{P} 2 \mathrm{~N}}$ & Temperature coefficients for decomposition, $\mathrm{PON}$ to $\mathrm{DON} / \mathrm{NH} 4$ & ${ }^{\circ} \mathrm{C}^{-1}$ & 0.0693 \\
\hline$K_{\mathrm{D} 2 \mathrm{~N}} / K_{\mathrm{O} 2 \mathrm{~S}}$ & Temperature coefficients for decomposition, DON to NH4/Opal to silicate & ${ }^{\circ} \mathrm{C}^{-1}$ & 0.0693 \\
\hline $\mathrm{RSiN}$ & $\mathrm{Si}: \mathrm{N}$ ratio & $\mathrm{mmol} \mathrm{Si}(\mathrm{mmol} \mathrm{N})^{-1}$ & 2.0 \\
\hline setVP/setVO & PON/Opal sinking velocity & $\mathrm{m} \mathrm{d}^{-1}$ & 20.0 \\
\hline
\end{tabular}

${ }^{\mathrm{a}}$ Most symbols for the biological parameters and their definitions are given by Kishi et al. [2007]. PL and PS are redefined to represent diatoms (PD) and flagellates (PF) in the model. ZS, ZL, ZP, DON, PON, and Opal: microzooplankton, mesozooplankton, predatory zooplankton, dissolved organic nitrogen, detrital particulate organic nitrogen, and particulate organic silica, respectively.

${ }^{\mathrm{b}}$ Parameter newly added into the biological model to parameterize dinoflagellates (microzooplankton) grazing on diatoms and described also in Appendix A.

as they are the only major phytoplankton group for which silicate is a limiting nutrient in the Arctic. The second phytoplankton component comprises all other major phytoplankton groups for which silicate is not limiting. Most of these major groups are flagellated and range in size from picophytoplankton to dinoflagellates. Because phytoplankton in both groups cover a broad size range, the large and small phytoplankton designations used in the Kishi et al. model were deemed inappropriate for the Arctic Ocean ecosystem. Here we designate the two groups as PD and PF for diatoms and flagellates, respectively. Some of the key biological parameters are adopted from the study of Walsh et al. [2005] for the Arctic Ocean, such as the maximum growth rate for flagellates and the half-saturation constants for uptake of nitrate, ammonium, and silicate (Table 1). The maximum growth rate for diatoms is based on observations compiled by Geider et al. [1997], which showed that the maximum growth rate for four diatom groups ranges from 1.5 to $4.3 \mathrm{~d}^{-1}$. In addition, grazing by microzooplankton on diatoms has been added to the original Kishi et al. [2007] model based on observations that heterotrophic dinoflagellates can be important grazers of diatoms in the Arctic (E. Sherr, personal communication, 2009). The corresponding changes in the Kishi et al. [2007] model equations and newly added terms are described in Appendix A.

[15] The model estimates the absorption of PAR in the water column following $\operatorname{PAR}(z)=\operatorname{PAR} f r a c \times E_{0} \exp \left[\left(-\alpha_{1}-\right.\right.$ $\left.\alpha_{\mathrm{S}} \mathrm{PF}-\alpha_{\mathrm{L}} \mathrm{PD}\right) z$, where PARfrac is the fraction of shortwave radiation that is photosynthetically active; $E_{0}$ is the net shortwave radiation on the ocean surface; $\alpha_{1}, \alpha_{\mathrm{S}}$, and $\alpha_{\mathrm{L}}$ are 


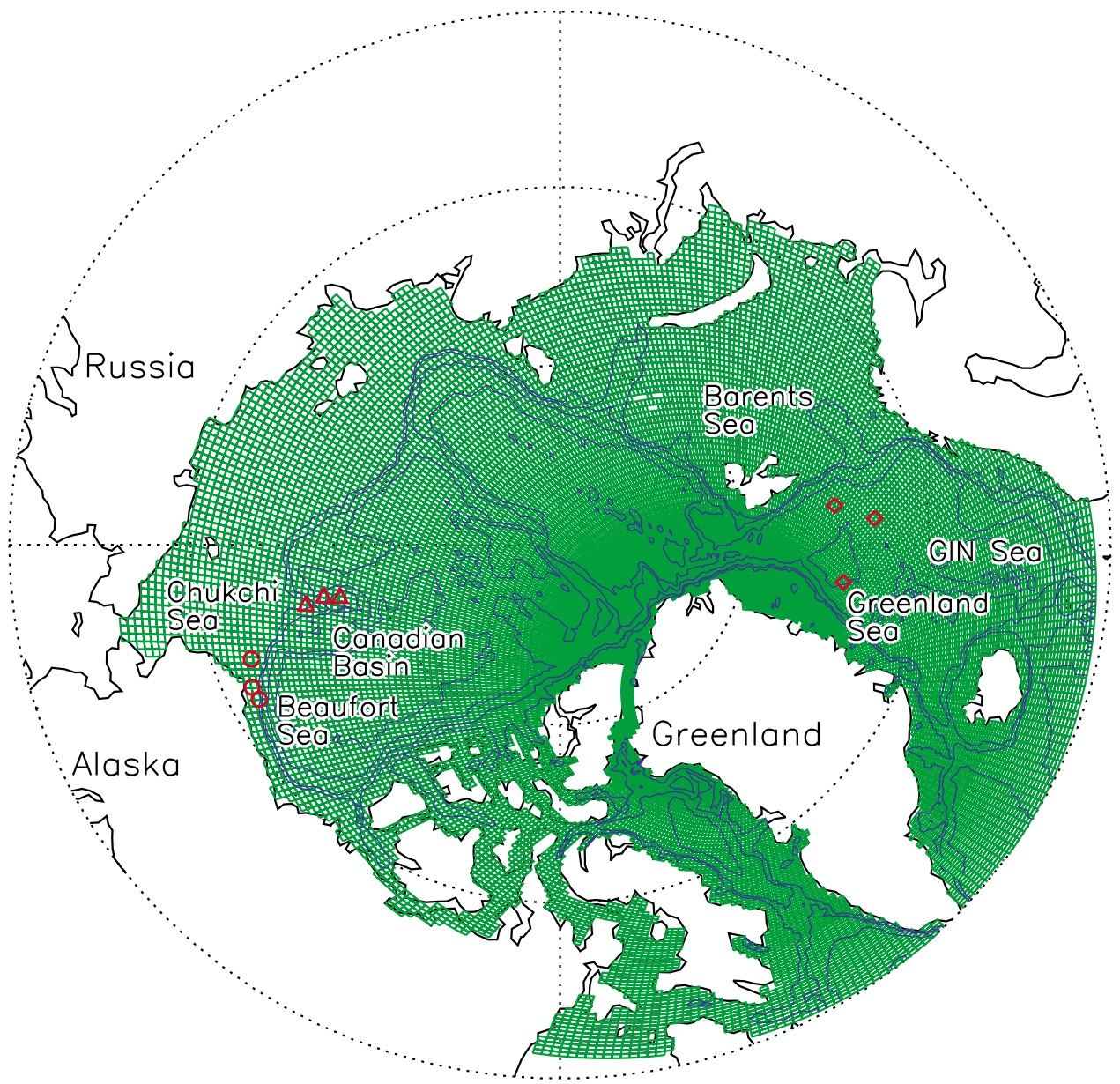

Figure 1. Grid configuration and bathymetry of the coupled 3-D pan-Arctic biology/sea ice/ocean model; bathymetry contours of 400, 800, 2200, and $3600 \mathrm{~m}$ are plotted. Marked are locations with in situ observations in the Greenland Sea (diamonds), along the SHEBA drift track in the Canadian Basin (triangles), and at the SBI stations in the Chukchi/Beaufort seas (circles).

light attenuation coefficients due to seawater and flagellates and diatoms; and $z$ is depth (see Table 1 and Kishi et al. [2007]). $E_{0}$ is calculated by the sea ice model following Maykut and Untersteiner [1971] and Hibler [1980]; shortwave radiation is allowed to penetrate through snow and sea ice, with an attenuation coefficient of $20 \mathrm{~m}^{-1}$ for snow [Grenfell and Maykut, 1977] and $1.5 \mathrm{~m}^{-1}$ for ice [Maykut and Untersteiner, 1971]. The value of PARfrac depends on various factors such as solar zenith angle and cloudiness and ranges from 0.39 to 0.53 globally [Pinker and Laszlo, 1992]. For simplicity, we use a constant value of PARfrac $=0.43$ for this study (Table 1). Model calibration and validation have been performed using satellite remote sensed and in situ observations (see section 3).

\subsection{Numerical Framework, Forcing, and Initial Conditions}

[16] The domain of the numerical biology/ice/ocean model covers the Arctic Basin, Chukchi, Beaufort, Barents, and GIN (Greenland-Iceland-Norwegian) seas, and Baffin Bay (Figure 1). The model grid configuration is based on a generalized orthogonal curvilinear coordinate system with the "North Pole" of the grid displaced into Greenland. The mean horizontal resolution is about $22 \mathrm{~km}$. To better resolve the mixed layer and the pycnocline, the ocean's vertical dimension has 30 levels of different thicknesses, with 13 levels in the upper $100 \mathrm{~m}$ and the top six of them being $5 \mathrm{~m}$ thick.

[17] A simple treatment is implemented for the model's open boundaries at Bering Strait and across the Atlantic Ocean around $60^{\circ} \mathrm{N}$ (Figure 1). Inflow and outflow along the open boundaries are not allowed because of a lack of information about the biogeochemical exchange between the Arctic Ocean and its adjacent seas. However, to mimic nutrient inflow at Bering Strait and biogeochemical exchange between the Arctic and the Atlantic, the nitrate and silicate, as well as temperature and salinity, along the open boundaries and in their vicinity are restored to monthly climatology data from the World Ocean Atlas 2005 [Garcia et al., 2006]. Such climatology restoring also prevents the physical and biogeochemical states at and near the open boundaries from drifting away from reality. The restoring constant ranges from 10 days along the open boundaries to infinity (no restoring) four grid cells away from the boundaries. No climatological restoring is allowed in the interior of the ocean. 
[18] Daily surface atmospheric forcing for 1977-2007 is used to drive the biophysical model. The atmospheric forcing is from the NCEP/NCAR reanalysis, which consists of surface winds, surface air temperature, humidity, downwelling longwave and shortwave radiative fluxes, precipitation, and evaporation. Model input also includes climatological river runoff of freshwater based on the study by Hibler and Bryan [1987]. River runoff of nutrients and organic matter are not incorporated. This model shortcoming affects the coastal areas near the mouth of major rivers (see Figure 9), so these areas are not the focus of this study.

[19] The model integration includes an 11 year spin-up, which is driven by the daily NCEP/NCAR forcing from 1977 to 1987. The initial conditions for the spin-up consist of 1 January 1977 fields of sea ice and ocean state variables simulated by Zhang et al. [2008], January mean climatology fields of nitrate and silicate from the World Ocean Atlas, and uniform distribution $\left(0.02 \mathrm{mmol} \mathrm{N} \mathrm{m}^{-3} ; 0.02 \mathrm{mmol} \mathrm{Si} \mathrm{m}^{-3}\right)$ of plankton and other biogeochemical components somewhat arbitrarily set for the upper $200 \mathrm{~m}$. During the 10 year spin-up, the coupled model adjusts itself and approaches an approximate steady state such that the year-to-year changes (from 1987 to 1988) in annual mean stocks of phytoplankton, zooplankton, and nitrate, averaged over the upper $100 \mathrm{~m}$ of the Arctic Ocean, are $-0.0005(1.0),-0.0003(0.3)$, and $0.1040(1.0) \mathrm{mmol} \mathrm{N} \mathrm{m}^{-3}(\%)$, respectively. After the spinup, the model proceeds to simulate the period of 1988-2007.

\section{Results}

[20] The Arctic Ocean is defined here as all open water and sea ice-covered areas north of the Arctic Circle at about $66.5^{\circ} \mathrm{N}$ following Pabi et al. [2008]. Ice-covered areas are those with ice concentration $\geq 0.15$. Model results of sea ice, PAR, and biology for the period 1988-2007 over open water and ice-covered areas of the Arctic Ocean demonstrate changes in the physical environment under declining sea ice and concurrent changes in light and nutrient availability and the impact of those changes on the marine planktonic ecosystem.

\subsection{Changes in Arctic Sea Ice, PAR, Water Temperature, and Nutrient Input, and Comparisons With Sea Ice Data}

[21] Comparisons of model-simulated and satelliteobserved yearly and summer (July-September) mean Arctic sea ice extent (Figure 2a) demonstrate that the model tends to overestimate ice extent, but it captures the interannual variability of the observed ice extents. The simulated ice extents are significantly correlated with satellite observations over 1988-2007 $(R=0.84,0.90$; Figure 2a), with low RMS (rootmean-square) error of $2 \%$ and $4 \%$. The simulated spatial patterns of ice extent (as shown by the simulated spatial thickness distribution) are also in a reasonably good agreement with the observations in August (Figure 3) when total PP in the Arctic Ocean is the highest (see Figure 15). Both model results and satellite observations show a generally downward trend in ice extent over 1988-2007 (Figure 2a). The decrease in ice extent in summer 2007 is particularly steep (Figures 2a and 3o), as was reported previously [e.g., Kerr, 2007; Stroeve et al., 2008; Comiso et al., 2008].
[22] The simulated total ice volume has decreased steadily from 1988 to 2007 (Figure 2b). This is because ice thickness has decreased over most of the Arctic Ocean (Figure 3), as also observed by submarine cruises [Rothrock et al., 1999, 2008]. The model overestimates ice thickness in the Canadian Archipelago region (Figure 3) compared with satellite-derived data [Laxon et al., 2003], indicating that the model may need finer resolution in that region to better resolve the narrow channels there. However, the model is able to capture the temporal and spatial variability of submarine observations of ice draft (equal to approximately $89 \%$ of ice thickness) along the tracks of submarine cruises during 1988-1997 in the central Arctic [see Rothrock et al., 2003], with a correlation of 0.87 and RMS error of $21 \%$ (Figure 4 ). Like ice thickness, snow depth has also decreased over 1988-1997 (not shown).

[23] Changes in ice extent and thickness and snow depth affect PAR at the ocean surface because of changes in surface albedo and light penetration through ice. The simulated annual mean total PAR of the Arctic Ocean varies from year to year in both open water and sea ice-covered areas (Figure 2c). The simulated total PAR in open water areas is highly correlated with the observed summer ice extent $(R=-0.92)$. Since 1988 the simulated total PAR over open water areas is generally increasing, from $104 \mathrm{TW}$ in 1988 to $150 \mathrm{TW}$ in 2007, simply because of decreasing summer ice extent that lowers surface albedo for enhanced net shortwave radiation, the ice-albedo feedback known to amplify the surface absorption of solar energy [e.g., Zhang et al., 2000; Lindsay and Zhang, 2005; Perovich et al., 2007, 2008]. The simulated annual mean total PAR (PAR per unit area) in icecovered areas of the Arctic Ocean increases during 19882007, from $42 \mathrm{TW}\left(4.7 \mathrm{Wm}^{-2}\right)$ in 1988 to $59 \mathrm{TW}\left(8.0 \mathrm{Wm}^{-2}\right)$ in 2007 (Figure 2c) because of the steadily thinning ice cover that leads to strengthened light penetration through ice for increased magnitude of PAR under ice (Figure 3). The total PAR (mean PAR per unit area) in all areas of the Arctic Ocean has increased from $146 \mathrm{TW}\left(11.4 \mathrm{Wm}^{-2}\right)$ in 1988 to $209 \mathrm{TW}\left(16.3 \mathrm{Wm}^{-2}\right.$ ) in 2007 (Figure 2c), although the NCEP/NCAR cloud fraction data for the Arctic Ocean show a positive linear trend of $0.0007 \mathrm{yr}^{-1}$ over the spring and summer of 1988-2007 with a corresponding decrease in downwelling shortwave radiation (not shown), owing likely to increasing open water.

[24] As Arctic sea ice declines with enhanced absorption of solar energy in the ocean, the model simulated water temperature in the upper $100 \mathrm{~m}$ of the Arctic Ocean increases over $1988-2007$, from $-0.5^{\circ} \mathrm{C}$ in 1988 to $0^{\circ} \mathrm{C}$ in 2007. This is compatible with the observations that surface waters in the Arctic Ocean peripheral seas warmed during 1965-2007 [Steele et al., 2008]. The increase in ocean temperature occurs as surface air temperature (SAT) increases. From 1988 to 2007, SAT over the Arctic Ocean has increased by more than $2^{\circ} \mathrm{C}$ (Figure 2d), according to the NCEP/NCAR reanalysis data.

[25] The model also simulates a generally increasing trend in the nitrate input into the upper $100 \mathrm{~m}$ (Figure $2 \mathrm{~g}$ ) as well as the upper $50 \mathrm{~m}$ (not shown), owing to vertical advection (upwelling/downwelling) and diffusion. The simulated nitrate input into the upper $100 \mathrm{~m}$ is closely correlated to the simulated magnitude of surface ocean stress and surface ocean stress curl $(R=0.73$ and 0.81 ; Table 2$)$. The significant 

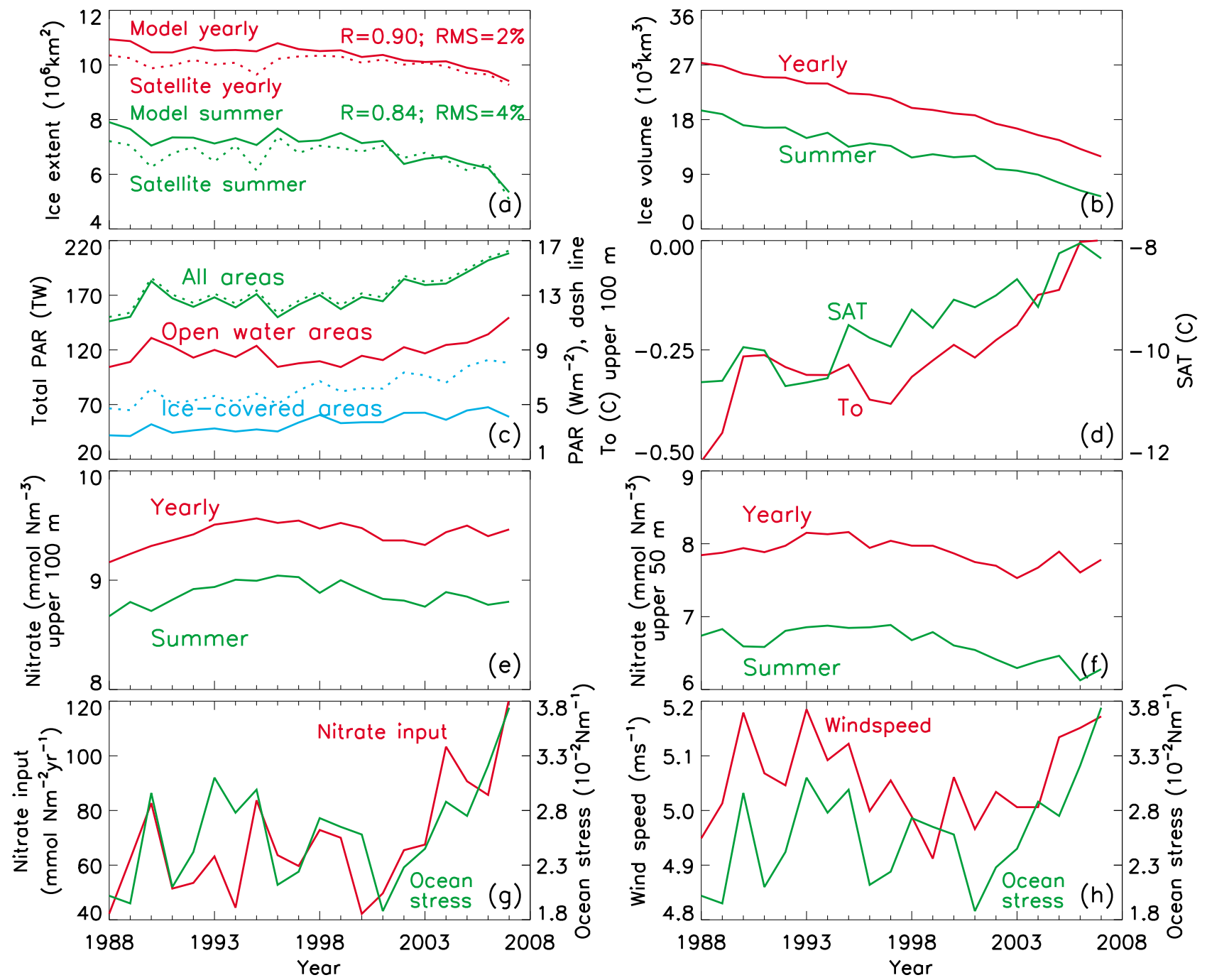

Figure 2. (a) Simulated and satellite-observed yearly and summer (July-September) mean Arctic sea ice extent; (b) simulated yearly and summer mean total sea ice volume; (c) simulated yearly mean total PAR (solid line) in open water, ice-covered, and all (open water plus ice-covered) areas of the Arctic Ocean and yearly mean PAR per unit area (dash line) in ice-covered and all areas; (d) yearly mean simulated ocean temperature (To) in the upper $100 \mathrm{~m}$ of the Arctic Ocean and NCEP/NCAR surface air temperature (SAT); simulated yearly and summer mean nitrate concentration in the upper (e) $100 \mathrm{~m}$ and (f) $50 \mathrm{~m}$; (g) simulated yearly mean nitrate input into the upper $100 \mathrm{~m}$ due to vertical advection and diffusion and magnitude of ocean surface stress; and (h) yearly mean NCEP/NCAR reanalysis surface wind speed in comparison with the simulated magnitude of ocean surface stress. The nitrate input into the upper $100 \mathrm{~m}$ in Figure $2 \mathrm{~g}$ is obtained by calculating the vertical advection and diffusion of nitrate at the $100 \mathrm{~m}$ depth. Model-data correlation $(R)$ and root-mean-square (RMS) error are indicated in Figure 2a. Satellite ice concentration data are acquired from NCEP (ftp://polar.ncep.noaa.gov/pub/cdas).

increase in the nitrate input in recent years corresponds to a significant increase in the surface ocean stress (Figure $2 \mathrm{~g}$ ) and the stress curl (not shown), which tends to enhance upwelling and mixing in the water column. The surface ocean stress is calculated following Hibler and Bryan [1987]. In open waters, the surface ocean stress consists of wind stress; in ice-covered areas, it consists of a summation of wind stress and ice internal interaction force. Thus, it is not surprising that changes in the simulated surface ocean stress (and stress curl) are linked to those in the surface winds (Figure 2h), with a correlation of $R=0.69$ between the magnitude of the surface ocean stress and the surface wind speed (Table 2).

[26] However, surface ocean stress (and stress curl) in the ice-covered areas is also linked to the state of sea ice (thickness, concentration, and extent) that tends to modify the air-sea momentum transfer by insulating the ocean from the overlying winds, as is reflected in the ice interaction force [Hibler and Bryan, 1987]. For example, high average wind speeds over the Arctic Ocean were observed in 20062007 and also in 1990 and 1993; however, the magnitude of surface ocean stress in 2006-2007 is significantly higher 

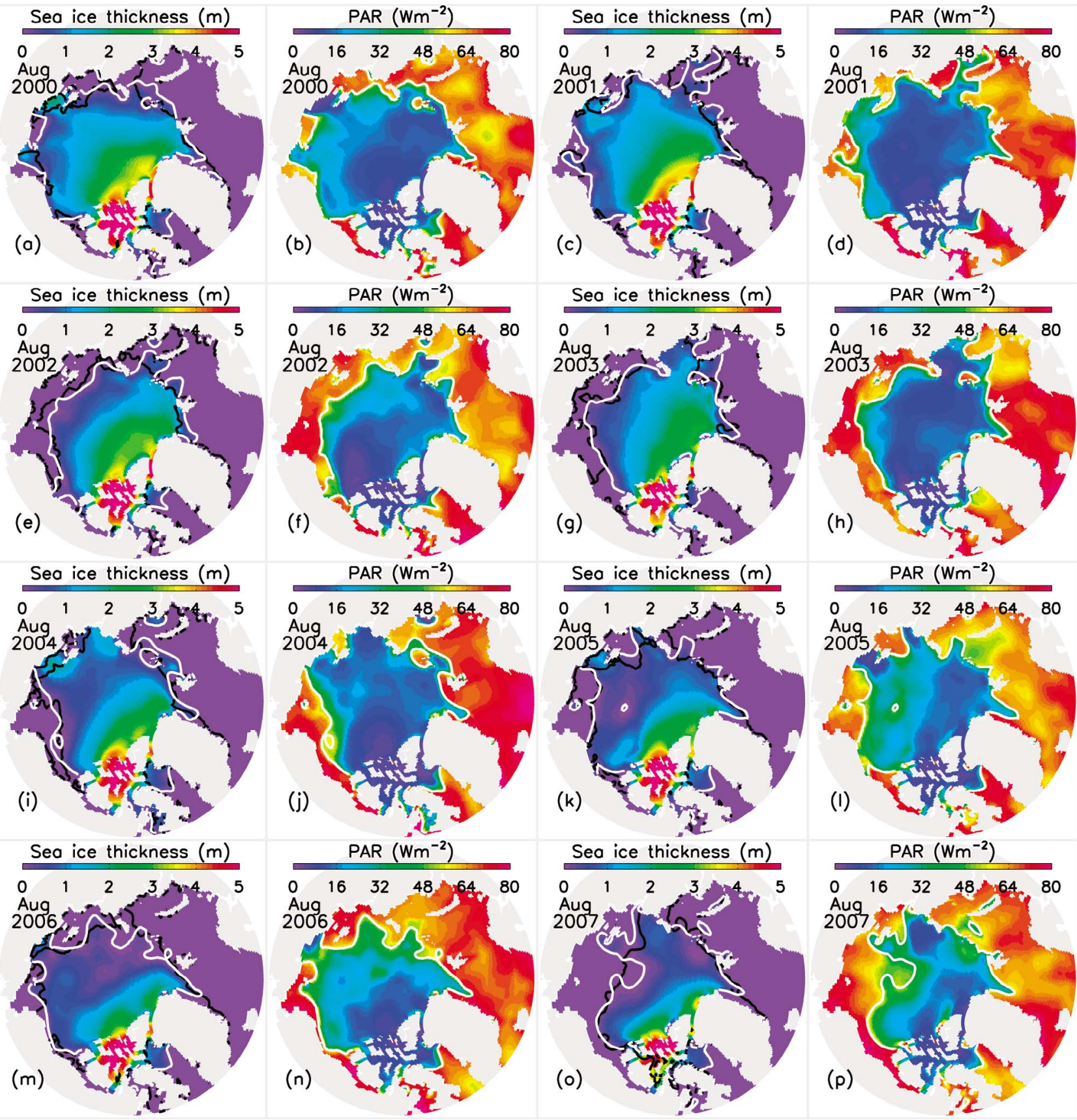

Figure 3. Simulated mean sea ice thickness and PAR for Augusts of 2000 through 2007. White line represents model simulated ice edge, and black line indicates satellite-observed ice edge defined as 0.15 ice concentration. (p) Note enhanced under-ice PAR north of the Chukchi Sea in 2007, relative to earlier years.

than in 1990 and 1993 (Figure 2h). This is because sea ice is thinner with less coverage in 2006-2007 than in 1990 and 1993 (Figures 2a and 2b), leading to a weakened insulation effect or strengthened air-sea momentum transfer. In other words, the diminution of sea ice results in increased light availability and increased nutrient input into the upper ocean layers through enhanced air-sea momentum transfer, or wind stirring, at the ocean surface and therefore strengthened vertical advection (mainly upwelling) and mixing.
[27] The simulated summer mean nitrate concentration is much lower than the yearly mean in either the upper $100 \mathrm{~m}$ or the upper $50 \mathrm{~m}$ (Figures $2 \mathrm{e}$ and $2 \mathrm{f}$ ), indicating that nutrient drawdown occurs in summer as suggested by observations [e.g., Gosselin et al., 1997; Lee and Whitledge, 2005; Tremblay et al., 2008; Codispoti et al., 2005, 2009]. The simulated yearly mean nitrate concentration in the upper $50 \mathrm{~m}$ and the yearly and summer mean nitrate concentrations in the upper $100 \mathrm{~m}$ are not correlated with PP (Table 2). 


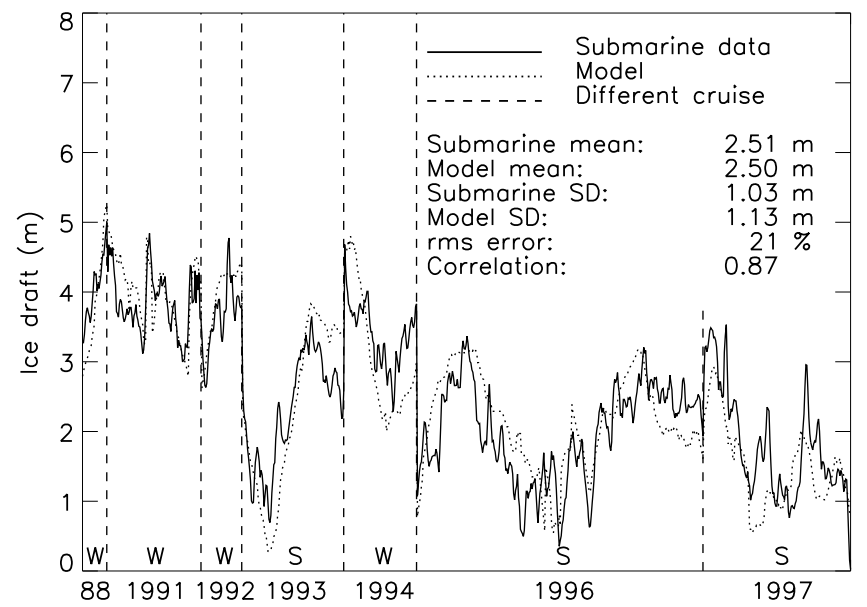

Figure 4. Model-simulated (dotted) and submarineobserved (solid) sea ice draft along the tracks of submarine cruises 1988-1997. The submarine ice draft data are described in the study by Rothrock et al. [2003]. SD, standard deviation; $\mathrm{W}$, winter cruise; $\mathrm{S}$, summer cruise.

However, the simulated summer nitrate concentration in the upper $50 \mathrm{~m}$ is significantly negatively correlated with the simulated PP $(R=-0.71$; Table 2$)$, indicating the close relationship between summer PP and nutrient drawdown. There is a significant decreasing trend in the summer nitrate concentration in the upper $50 \mathrm{~m}$ during $1988-2007$. This is because of an increase in the simulated PAR, PP, and hence nutrient uptake in recent years as sea ice retreats ( $\mathrm{PP}$ is described in sections 3.3-3.4). However, even with an increased summer nutrient uptake in recent years, no significant decreasing trend is simulated for the yearly mean nitrate concentration in the upper $50 \mathrm{~m}$ and the yearly and summer mean nitrate concentrations in the upper $100 \mathrm{~m}$ over 1988-2007. This may be linked to the simulated increasing trend in the yearly mean nitrate input into the upper layers.

\subsection{Daily Evolution of the Planktonic Ecosystem and Comparisons With In Situ Data}

[28] Our investigation of the daily evolution of the simulated ecosystem and comparison with in situ observations focuses on PP, chlorophyll $a$ (chl $a$ ), flagellates, diatoms, microzooplankton, mesozooplankton, predatory zooplankton, and nitrate in three different regions: a mostly ice-free (open water) area in the Greenland Sea in 1999 where some biological data are available (Figure 5), a permanently (except summer 2007) ice-covered area in the Canadian Basin where SHEBA data are available for 1997-1998 (Figure 6), and a seasonally ice-covered area in the Chukchi and Beaufort seas where SBI data are available for 2002 and 2004 (Figure 7). In Figures 5-7, the limited in situ observations are shown. Also shown are simulated daily variations of PAR, ice thickness, and snow depth (where available). Note that the basic currency of the biological model components is nitrogen $\left(\mathrm{mmol} \mathrm{N} \mathrm{m}{ }^{-3}\right.$ ), which needs to be converted to carbon (C) and chl $a$ for model-data comparisons. We follow Lavoie et al. [2009] to use a fixed $\mathrm{C} / \mathrm{N}$ (mol-mol) ratio of 106:16 [Redfield et al., 1963] and a fixed N/chl $a(\mathrm{wt} / \mathrm{wt})$ ratio of $8.75: 1$ for the unit conversions.

[29] Because of stronger light limitation in a year-round icecovered region (Figures 6i-6j), the simulated and observed spring bloom at the SHEBA locations in the Canadian Basin (Figure 6) occur later than in the open water area of the Greenland Sea (Figure 5) and the seasonally ice-covered Chukchi/Beaufort seas (Figure 7). The simulated timing of spring bloom, PP, and plankton biomass at the SBI locations show considerably more spatial variability than in the open water area of the Greenland Sea and in the permanently icecovered area of the Canadian Basin (Figures 5-7). Also, the simulated PP and plankton biomass tend to fluctuate substantially over summer and even early fall. Multiple peaks are often simulated, which are strongly time and location dependent. This is because of the substantial seasonal changes in ice/snow thickness (Figures $7 \mathrm{j}-7 \mathrm{k}$ ) in the seasonally icecovered area that tend to cause more spatial variations in PAR (Figure 7i) by modifying surface albedo [Perovich et al., 2007; 2008] and light penetration through sea ice. Seasonal changes in ice thickness may also cause more variations in nutrient availability in the euphotic zone by altering surface momentum and buoyancy fluxes and hence the vertical mixing processes [Sambrotto et al., 1986; Wassmann et al., 1996]. In addition, seasonal changes in ice conditions may result in more temporal and spatial variations in oceanic processes

Table 2. Correlations Among the Simulated Yearly Mean Nitrate Concentration, Mean Nitrate Input, Magnitude of Surface Ocean Stress and Surface Ocean Stress Curl, Surface Wind Speed, Photosynthetically Active Radiation, Ocean Temperature, and Primary Productivity Over the Period $1988-2007^{\mathrm{a}}$

\begin{tabular}{|c|c|c|c|c|c|c|c|c|c|c|}
\hline & N100y & $\mathrm{N} 100 \mathrm{~s}$ & N50y & $\mathrm{N} 50 \mathrm{~s}$ & Nin & SOS & OSC & $\mathrm{SWS}^{\mathrm{b}}$ & PAR & PP \\
\hline N100y & & 0.87 & 0.52 & 0.25 & 0.22 & & & & & 0.21 \\
\hline N100s & & & 0.63 & 0.60 & -0.12 & & & & -0.35 & -0.25 \\
\hline N50y & & & & 0.86 & -0.25 & & & & & -0.30 \\
\hline $\mathrm{N} 50 \mathrm{~s}$ & & & & & -0.54 & & & & -0.83 & -0.71 \\
\hline Nin & & & & & & 0.73 & 0.81 & 0.42 & & 0.70 \\
\hline SOS & & & & & & & 0.98 & 0.69 & & \\
\hline OSC & & & & & & & & 0.69 & & \\
\hline $\mathrm{SWS}^{\mathrm{b}}$ & & & & & & & & & & \\
\hline PAR & & & & & & & & & & 0.96 \\
\hline To & & & & & & & & & & 0.95 \\
\hline
\end{tabular}

${ }^{\mathrm{a}}$ Correlations among simulated yearly (N100y) and summer (N100s) mean nitrate concentration in the upper $100 \mathrm{~m}$, yearly (N50y) and summer (N50s) mean nitrate concentration in the upper $50 \mathrm{~m}$, and yearly mean nitrate input into the upper $100 \mathrm{~m}$ (Nin), magnitude of surface ocean stress (SOS) and surface ocean stress curl (OSC), surface wind speed (SWS), surface PAR, and ocean temperature $(T \mathrm{o})$ and PP in the upper $100 \mathrm{~m}$, averaged in all areas of the Arctic Ocean over the period 1988-2007.

${ }^{\mathrm{b}}$ Calculated from the NCEP/NCAR reanalysis data, not simulated by the model. 


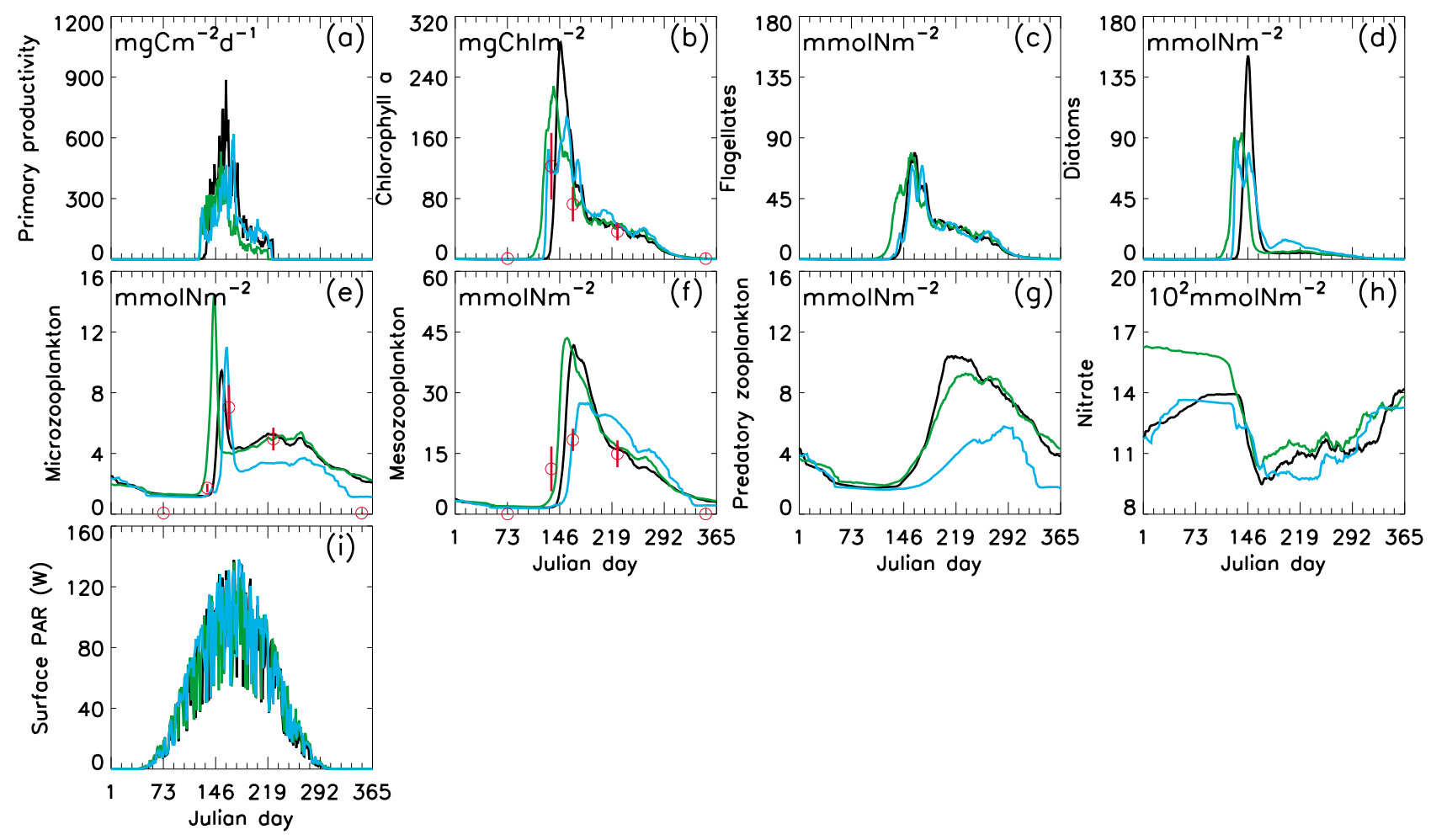

Figure 5. Daily variations of the modeled biogeochemical variables integrated over the (a-h) upper $100 \mathrm{~m}$ and (i) surface PAR in 1999 at three measurement locations in the Greenland Sea represented by the different colored lines. Circle and vertical line represent mean value and error bar of observations collected primarily in 1999 [Møller et al., 2006]. The three measurement locations, marked by diamonds in Figure 1, are $\left(8.48^{\circ} \mathrm{E}, 75.00^{\circ} \mathrm{N}\right.$, depth $\left.2774 \mathrm{~m}\right)$, black line; $\left(5.00^{\circ} \mathrm{E}, 72.92^{\circ} \mathrm{N}, 2309 \mathrm{~m}\right)$, green; and $\left(7.72^{\circ} \mathrm{W}, 74.55^{\circ} \mathrm{N}, 3308 \mathrm{~m}\right)$, blue.

such as advection and diffusion of biogeochemical tracers by modifying the ocean circulation in the shelf region.

[30] Model-data comparisons show that the model is able to basically capture the timing and magnitude of spring bloom in the Greenland Sea and the Chukchi/Beaufort seas (Figures 5 and 7). They also reveal that the model simulated timing of the spring bloom is delayed considerably in the permanently ice-covered area of the Canada Basin along the SHEBA drift track, although the simulated chl $a$ and phytoplankton biomass in the ice-covered SHEBA area are generally within or close to the range of the observations (Figure 6). What causes the delay? The simulated seasonal cycle of ice thickness (Figure 6j) does not appear to deviate substantially from that observed at the SHEBA site with multiyear ice [Perovich et al., 2003]. However, most of the 106 SHEBA measurements of snow depth are below $0.6 \mathrm{~m}$ in May 1998 [Perovich et al., 2003], while the simulated snow depth is close to $1 \mathrm{~m}$ (Figure 6k). The overestimation of snow depth may contribute to an underestimation of PAR in spring, thus resulting in the delay. The delay may be also attributed to uncertainties in model parameters governing photosynthesis such as phytoplankton photoinhibition and photochemical reaction coefficients. Phytoplankton in permanently ice-covered areas may be dark-adapted and the photosynthesis processes may be significantly different from those in permanent open water areas or seasonally icecovered areas.
[31] The delay in the simulated phytoplankton bloom in the permanently ice-covered SHEBA area affects the consumers of primary production, and the model significantly delays the timing and underestimates the magnitude of the zooplankton biomass peaks (Figures 6e and 6f). For the mesozooplankton, much of this discrepancy can be attributed to the seasonal upward vertical migration of large, biomass dominant species from depth, which is a dominant component of the timing and magnitude of this peak [Ashjian et al., 2003]. This is not accounted for in the model, as only growth and mortality are considered. In addition, it should be noted that the ice station drifted through several different water masses, covered a range of water depths and encountered different zooplankton communities [Ashjian et al., 2003], which may have altered the true seasonal patterns to some degree. Furthermore, the lack of sea ice algae in the model may contribute to the bias in zooplankton biomass. This suggests the importance of incorporating ice algae in the model for ice-covered areas where ice algae may contribute up to $57 \%$ of the combined water column and sea ice primary production [Gosselin et al., 1997]. The underestimation of zooplankton biomass also may be due to uncertainties in model parameters such as zooplankton grazing and mortality rates under thick ice and/or cold temperatures. There is a lack of vital rate measurements for zooplankton at cold temperatures, especially in the Arctic, with the possible exception of egg production rates [e.g., Huntley and Lopez, 1992; Hirst and Bunker, 2003; Bunker and Hirst, 2004]. Thus, 

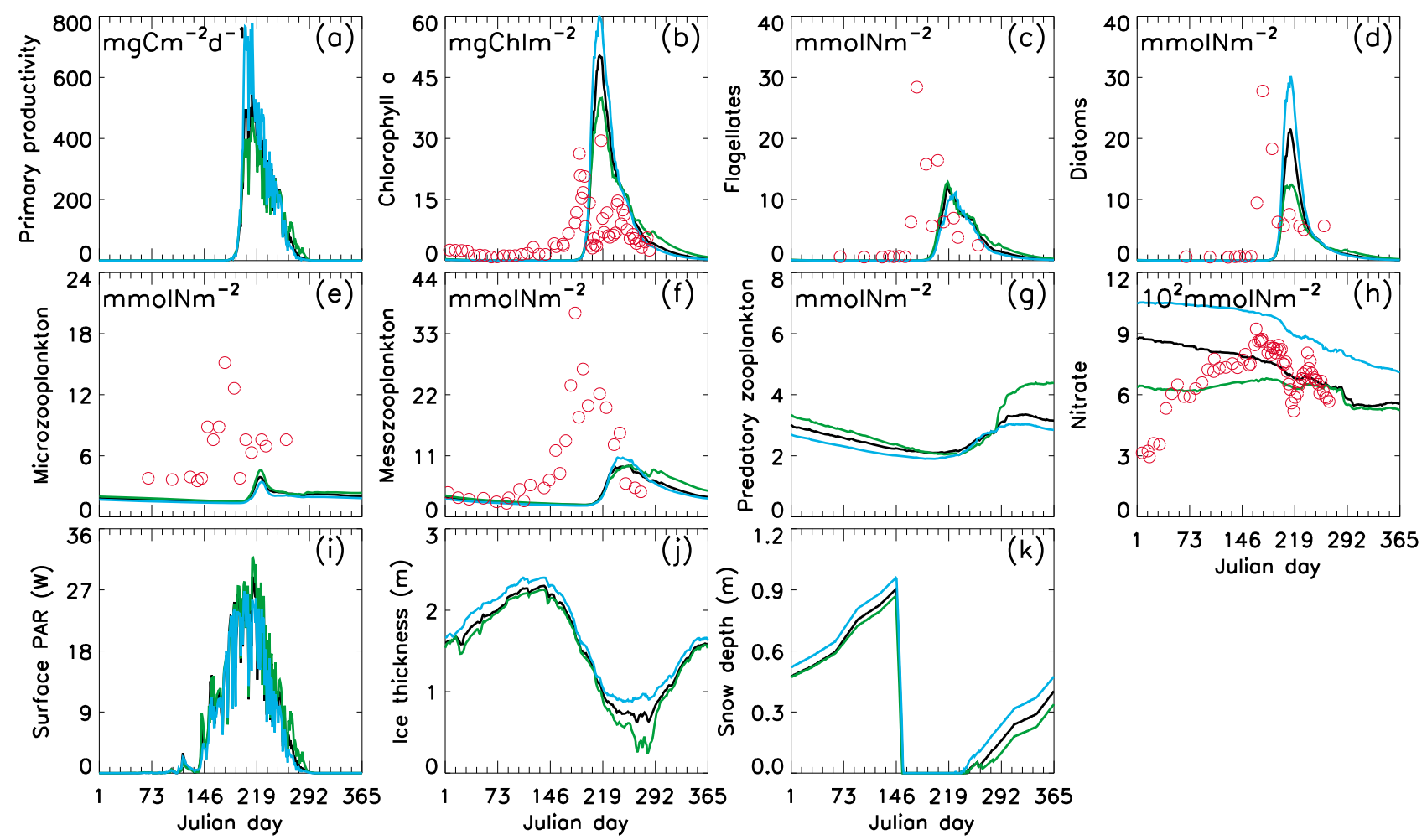

Figure 6. Daily variations of the modeled biogeochemical variables integrated over the $(\mathrm{a}-\mathrm{h})$ upper $100 \mathrm{~m}$, (i) surface PAR, (j) sea ice thickness, and (k) snow depth in 1998 at three SHEBA locations in the Canadian Basin. Circles represent SHEBA observations along the SHEBA track in 1998 reported by Ashjian et al. [2003] and Sherr et al. [2003]. The three locations, marked by triangles in Figure 1, are $\left(167.70^{\circ} \mathrm{W}\right.$, $76.95^{\circ} \mathrm{N}$, depth $\left.812 \mathrm{~m}\right)$, black line; $\left(166.70^{\circ} \mathrm{W}, 75.90^{\circ} \mathrm{N}, 289 \mathrm{~m}\right)$, green; and $\left(166.70^{\circ} \mathrm{W}, 77.80^{\circ} \mathrm{N}, 289 \mathrm{~m}\right)$, blue.

parameter estimates for rate processes need to be extrapolated to low temperatures where few or no data exist, possibly leading to inaccurate representations of these rates in models.

[32] In the SBI area in the Chukchi/Beaufort seas, the simulated PP and chl $a$ and mesozooplankton biomass are generally within or close to the range of the observations, with underestimation or overestimation from time to time and from location to location (Figures $7 \mathrm{a}, 7 \mathrm{~b}$, and 7f). In the Greenland Sea, the simulated chl $a$ and microzooplankton biomass (Figures $5 \mathrm{~b}$ and $5 \mathrm{e}$ ) are mostly close to the range of the observations from Møller et al. [2006], but mesozooplankton biomass may be overestimated (Figure $5 \mathrm{f}$ ).

[33] Comparison of model and in situ vertical profiles of chl $a$, PP, and nitrate from three SBI 2004 stations show a subsurface peak of chl $a$ and PP at about $20 \mathrm{~m}$ depth (Figure 8). However, the model underestimates the peak values of chl $a$ and PP at two stations located at $154.49^{\circ}$ $\mathrm{W} / 71.55^{\circ} \mathrm{N}$ and $159.11^{\circ} \mathrm{W} / 72.13^{\circ} \mathrm{N}$ (Figures $8 \mathrm{a}-8 \mathrm{~b}$ and $8 \mathrm{~g}-8 \mathrm{~h})$ and overestimates the peak value of PP and surface values of both chl $a$ and PP at the third station located at $152.13^{\circ} \mathrm{W} / 71.59^{\circ} \mathrm{N}$ (Figures $8 \mathrm{~d}-8 \mathrm{e}$ ). The low surface values of chl $a$ and PP are due to the summer surface depletion of nitrogen (Figures 8c, 8f, and 8i), which is the limiting nutrient as suggested by observations [Gosselin et al., 1997; Lee and Whitledge, 2005; Tremblay et al., 2008; Codispoti et al., 2005, 2009]. Because of a generally higher simulated biological productivity, summer reduction in nitrogen in the upper $100 \mathrm{~m}$ appears to be more severe in the open water area of the Greenland Sea and the seasonally ice-covered area of the Chukchi/Beaufort seas than in the permanently ice-covered area of the Canadian Basin (Figures 5h, 6h, and $7 \mathrm{~h}$ ).

\subsection{Monthly Variation of Primary Production and Comparisons With Satellite Data}

[34] Comparison of model-simulated and Sea-viewing Wide Field-of-view Sensor (SeaWiFS) observed monthly and yearly 1998-2007 mean surface chl $a$ concentration (Figure 9) reveals some regional differences in the magnitude of chl $a$ but similarities in the spatial extent and timing of the seasonal chl a maxima. In May, the model overestimates chl $a$ in part of the GIN seas but underestimates it in part of the Barents Sea (Figures 9a-9b). In June, the model generally overestimates chl $a$ in the Barents and Greenland seas (Figures 9c-9d). These differences are likely to be reflected in the model-simulated monthly and yearly 1998-2007 mean fields of PP in the upper $100 \mathrm{~m}$ (Figure 10), particularly in the Barents and Greenland seas during June (Figure 10c).

[35] In summer, because of penetration of light through sea ice, the model estimates significant surface chl $a$ concentration and PP in most of the permanently ice-covered central Arctic where SeaWiFS chl $a$ data are nonexistent because data retrievals are hindered by the ice cover 

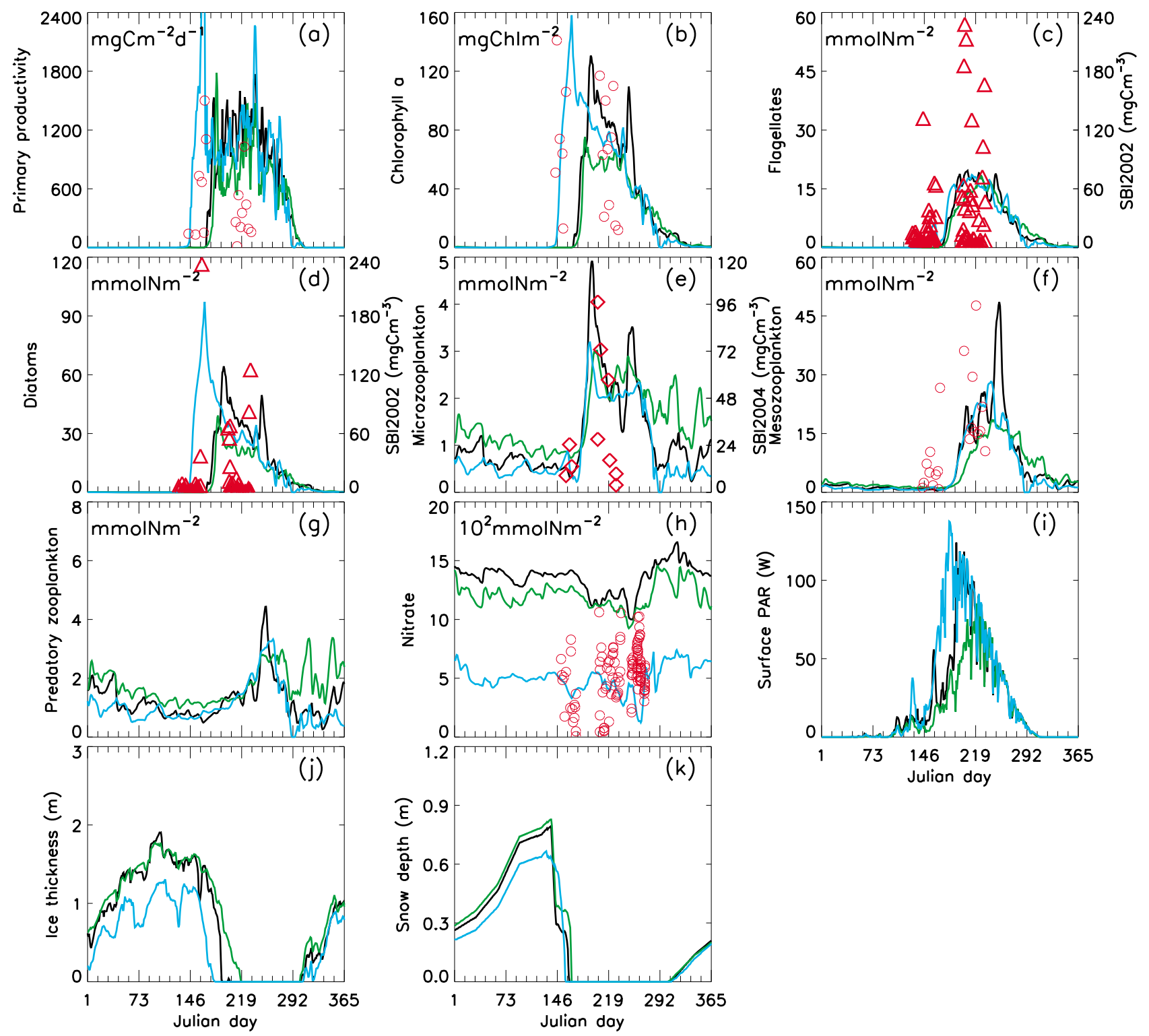

Figure 7. Daily variations of the modeled biogeochemical variables integrated over the $(a-h)$ upper $100 \mathrm{~m}$, (i) surface PAR, (j) sea ice thickness, and (k) snow depth in 2004 at three SBI stations in the Chukchi and Beaufort seas. Circles represent 2004 SBI observations integrated over the upper $100 \mathrm{~m}$, with PP, chl $a$, and mesozooplankton reported by Campbell et al. [2009] and nitrate archived at the NCAR Earth Observing Laboratory (EOL) Data Center (http://www.eol.ucar.edu/projects/sbi/). Triangles and diamonds represent 2002 SBI phytoplankton and 2004 SBI microzooplankton observations at various depths, also archived at the EOL Data Center; with different units than the model results, these observations are not for direct quantitative model-data comparisons but for illustration of the timing of spring bloom. The three locations, marked by circles in Figure 1 and also indicated in Figure 8, are $\left(154.49^{\circ} \mathrm{W}, 71.55^{\circ} \mathrm{N}\right.$, depth $\left.166 \mathrm{~m}\right)$, black line; $\left(152.13^{\circ} \mathrm{W}, 71.59^{\circ} \mathrm{N}, 1566 \mathrm{~m}\right)$, green; and $\left(159.11^{\circ} \mathrm{W}, 72.13^{\circ} \mathrm{N}, 43 \mathrm{~m}\right)$, blue.

(Figures $9 \mathrm{e}-9 \mathrm{j}$ and $10 \mathrm{~d}-10 \mathrm{f}$ ). In August in particular, the simulated surface chl $a$ concentration and PP in some icecovered areas are even higher than those in the open water and seasonally ice-covered areas of the Barents and GIN seas (Figures $9 \mathrm{~g}$ and 10e). This is because phytoplankton bloom occurs often in springtime in the open water and seasonally ice-covered areas, whereas it often occurs in summertime in ice-covered areas where light limitation is stronger (Figures 9 and 10a-10h). The earlier phytoplankton bloom in the open water and seasonally ice-covered areas of the Barents and GIN seas leads to a generally earlier and more severe nutrient drawdown (Figures 101-10n). The simulated nutrient drawdown appears to be also severe in the Chukchi, Beaufort, and Kara seas. Thus, in addition to light, nutrients are limiting phytoplankton growth in various regions of the Arctic Ocean, as indicated by observations [e.g., Gosselin et al., 1997; Tremblay et al., 2008; Codispoti et al., 2005, 2009]. 

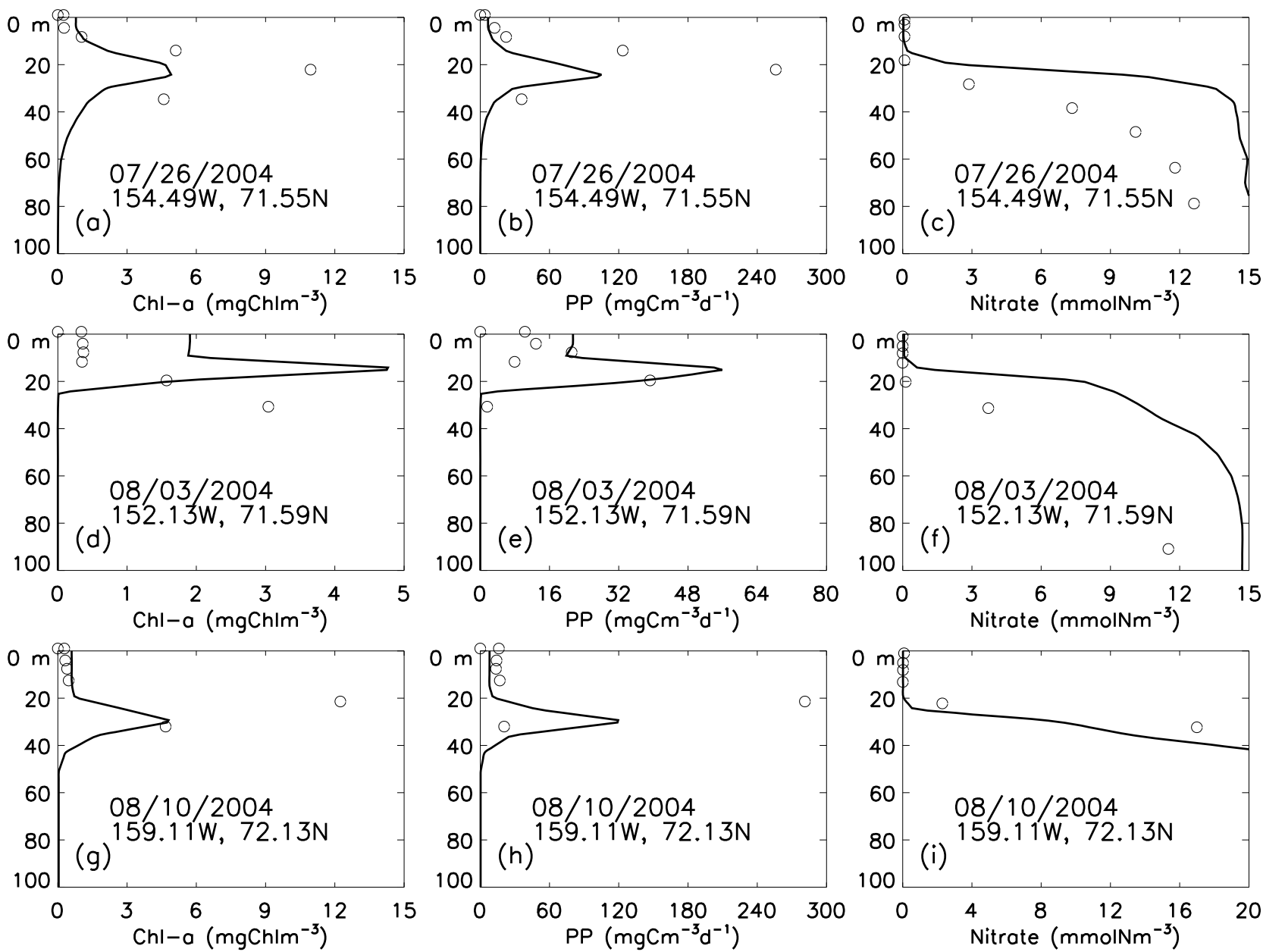

Figure 8. Vertical distribution of model simulated (line) and SBI observed (circle) chl $a$, PP, and nitrate at three SBI stations in the Chukchi and Beaufort seas. The date, longitude, and latitude of the SBI stations are indicated here and marked by circles in Figure 1. Nitrate is overestimated at depth at two locations. The nitrate data are available at the EOL Data Center (http://data.eol.ucar.edu/codiac/dss/id=62.175). The chl $a$ and PP data are available at http://psc.apl.washington.edu/cgi-bin/PPobs/PPobs.cgi.

[36] Compared to SeaWiFS chl $a$ data, the model might underestimate, to some degree, summer chl $a$ in some coastal areas of the East Siberian, Laptev, Kara, and Beaufort seas near the mouth of major arctic rivers such as Ob, Lena, Yenisey, and Mackenzie, even though SeaWiFS chl $a$ is biased high in these areas owing to the influence of riverine sediments and/or colored dissolved organic matter that have the potential to alter optical properties in coastal waters [Cota et al., 2004; Matsuoka et al., 2007; Pabi et al., 2008]. This underestimation near rivers may be attributed to the fact that the nutrient and dissolved organic matter loads from these rivers are not included in the model. In most of the Barents and GIN seas, the modeled surface chl $a$ generally agrees with the observations throughout the summer (deviation mostly below $0.3 \mathrm{mg} \mathrm{m}^{-3}$ ) (Figures $9 \mathrm{e}-9 \mathrm{j}$ ).

[37] The yearly 1998-2007 mean modeled surface chl $a$ display similar patterns as the SeaWiFS yearly composite chl $a$ in ice-free or seasonally ice-covered areas (Figures 9k-91). In these areas, the simulated long-term mean chl $a$ values are close to the observed chl $a$ values (deviation mostly below $0.3 \mathrm{mg} \mathrm{m}^{-3}$ ), and the simulated long-term (19882007) mean PP values (Figure 10h) appear to be close to the long-term mean PP values derived by Pabi et al. [2008] using SeaWiFS chl $a$ data (see Figure 12a in Pabi et al.). The spatial pattern of the simulated long-term mean PP for the Barents Sea appears to be similar to that simulated by Ellingsen et al. [2008]. In addition, the simulated mean PP values averaged for various Arctic shelves, the North Pole area, and the Greenland Sea over 1988-2007 are generally within the range of or close to observations [Carmack et al., 2006; Sakshaug, 2004; Gosselin et al., 1997; Richardson et al., 2005] (see Table 3). The simulated maximum PP values during 1988-2007 are greater than the observational estimates for Kara, Laptev, East Siberian, and Beaufort shelves (Table 3). This is likely due to the fact that the model simulates a significant increase in PP in recent years when ice declined substantially, whereas the observations were collected in earlier years with more ice.

\subsection{Changes in Arctic Marine Planktonic Ecosystem in Response to Declining Sea Ice}

[38] The observed ongoing decline in sea ice in recent years offers the opportunity to observe the ecosystem response to this decline using modeled ecosystem parameters. On an 

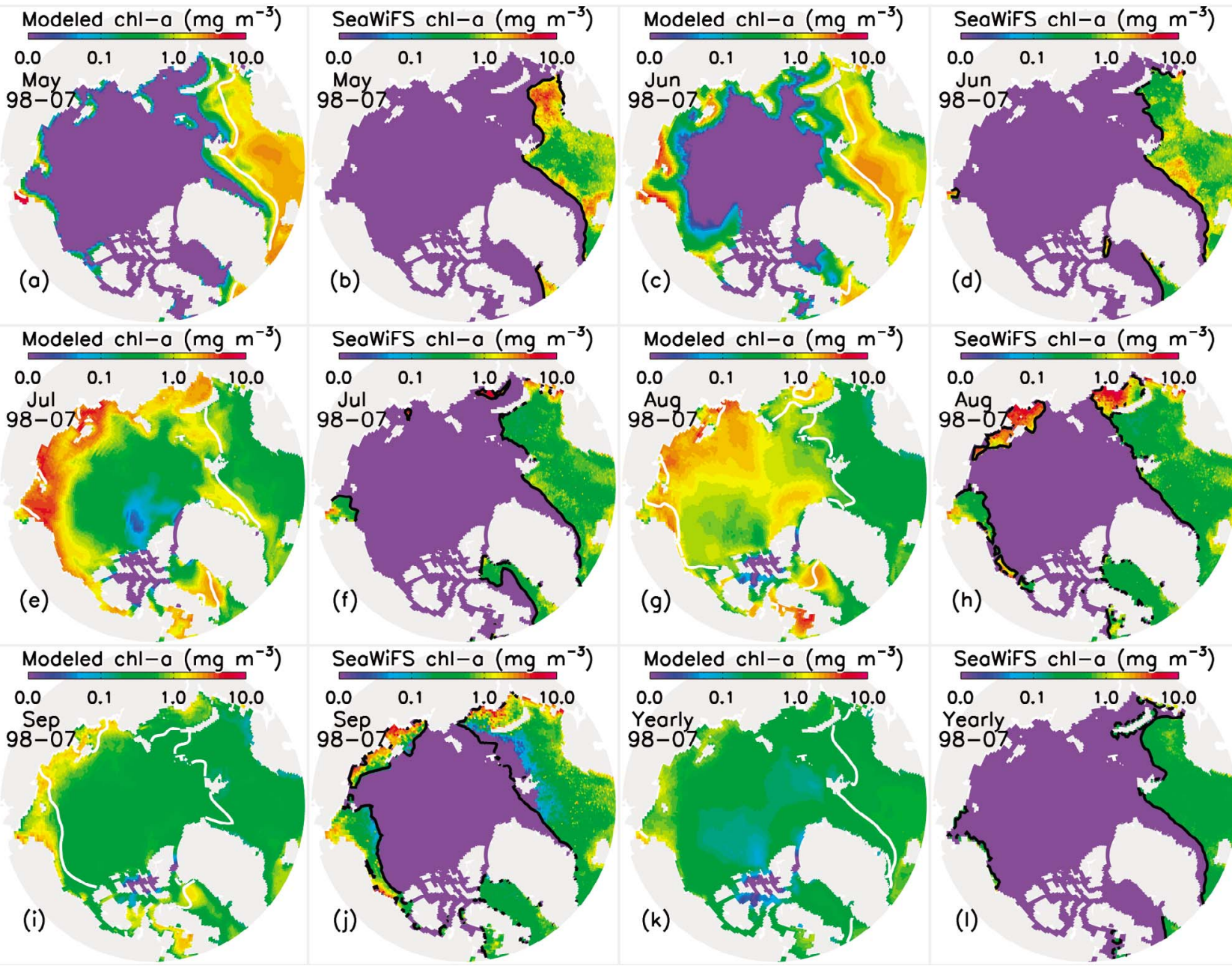

(h)
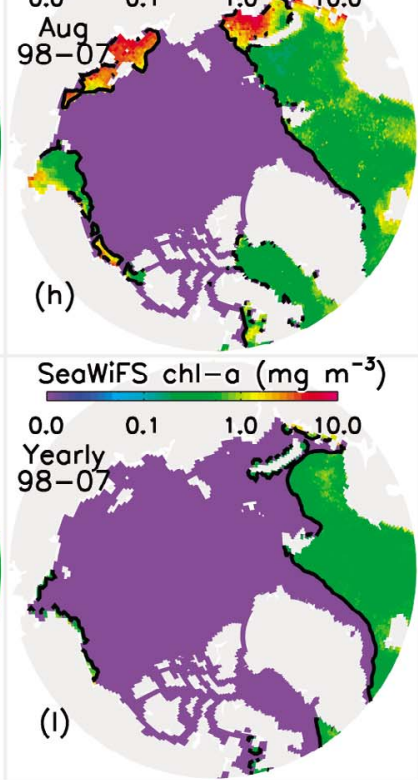

Figure 9. Model-simulated and SeaWiFS observed (a-j) monthly 1998-2007 mean and (k-1) yearly 1998-2007 mean surface concentration of $\operatorname{chl} a$. The white line represents corresponding model simulated ice edge, and black line indicates satellite-observed ice edge. Monthly composite SeaWiFS chl $a$ data are distributed by http://oceancolor.gsfc.nasa.gov. Note that SeaWiFS chl $a$ values are unreliable under ice and therefore not plotted.

annual basis, the magnitude of all simulated biological variables generally increases with decreasing sea ice cover and increasing PAR and nitrate input into the upper ocean layers during 1988-2007, particularly since 1996 (Figures 2 and 3, and 11). Changes in the simulated annual marine total PP or mean PP per unit area in the upper $100 \mathrm{~m}$ of the Arctic Ocean (Figure 11a) are highly correlated with the simulated PAR (Figure 2c). Correlations between the total PP and total PAR over $1988-2007$ are $R=0.95$ for open water areas, $R=0.97$ for ice-covered areas, and $R=0.96$ for all areas (Table 2). Changes in the simulated total PP for all areas are also significantly correlated with the nitrate input into the upper $100 \mathrm{~m}(R=0.70$, Table 2$)$. Thus, the recent increase in PP is closely linked to the decline in sea ice, which leads to an increase in PAR and nitrate input into the euphotic zone (Figures $2 \mathrm{c}$ and $2 \mathrm{~g}$ ). The increase in the water temperature in the upper $100 \mathrm{~m}$ of the Arctic Ocean (Figure 2d) also contributes to and is highly correlated $(R=0.95$, Table 2$)$ with the increase in PP because the simulated phytoplankton growth rates increase with rising water temperature when nutrients are not depleted.
[39] With decreasing sea ice extent, the simulated PP in the upper $100 \mathrm{~m}$ in open water areas of the Arctic Ocean increases generally during 1988-2007, especially since 1996 (Figure 11a). In particular, the simulated annual total PP (mean PP per unit area) in the upper $100 \mathrm{~m}$ is $344 \mathrm{Tg} \mathrm{C} \mathrm{yr}^{-1}$ $\left(105 \mathrm{~g} \mathrm{C} \mathrm{m}^{-2} \mathrm{yr}^{-1}\right)$ for 1988 and $520 \mathrm{Tg} \mathrm{C} \mathrm{yr}^{-1}\left(120 \mathrm{~g} \mathrm{C} \mathrm{m}^{-2}\right.$ $\mathrm{yr}^{-1}$ ) for 2007. There is a local PP maximum in 1990, which corresponds to a local minimum in ice extent (Figure 2a) and a local maximum in both PAR (Figure 2c) and the nitrate input into the upper $100 \mathrm{~m}$ (Figure 2g). From 1998 to 2007, the simulated annual total PP in open water areas is mostly in close agreement with that derived by Pabi et al. [2008] and Arrigo et al. [2008] using SeaWiFS surface chl $a$ mainly in open water areas, even though the SeaWiFS derivation may miss the subsurface chl $a$ maximum in some locations. The SeaWiFS-derived total PP is higher than the model simulated total PP in 2000 and 2001, with a local peak value in 2001 (Figure 11a). Note that ice extent in 2001 is not particularly low (Figure 2a). The local maximum in SeaWiFS-derived PP in 2001 is attributed to the result of both higher than normal phytoplankton biomass and higher 

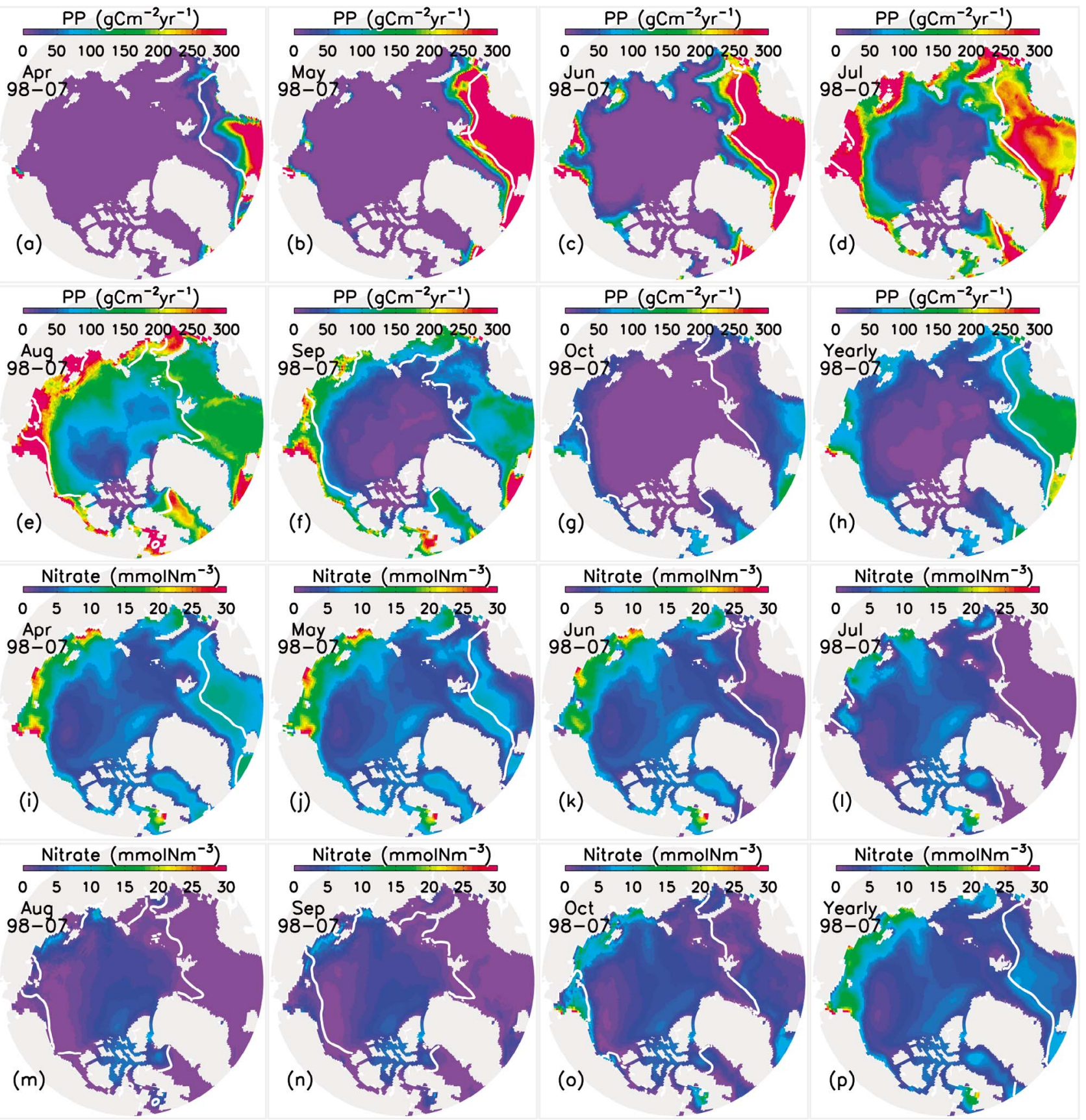

Figure 10. Simulated (a-g) monthly 1998-2007 mean and (h) yearly 1998-2007 mean PP in the upper $100 \mathrm{~m}$, and (i-o) simulated monthly 1998-2007 mean and (p) yearly 1998-2007 mean nitrate concentration in the upper $5 \mathrm{~m}$. The white line represents corresponding simulated ice edge.

area-normalized rates of production in summer of that year [Pabi et al., 2008], which is not reflected in the modeled PP associated with near-average PAR (Figure 2c) and relatively low nitrate input into the upper $100 \mathrm{~m}$ (Figure $2 \mathrm{~g}$ ) in 2001.

[40] Like the PAR in ice-covered areas, the simulated annual total PP (mean PP per unit area) in ice-covered areas has generally increased, from $112 \mathrm{Tg} \mathrm{C} \mathrm{yr}^{-1}\left(14 \mathrm{~g} \mathrm{C} \mathrm{m}^{-2} \mathrm{yr}^{-1}\right)$ in 1988 to $162 \mathrm{Tg} \mathrm{C} \mathrm{yr}^{-1}\left(23 \mathrm{~g} \mathrm{C} \mathrm{m}^{-2} \mathrm{yr}^{-1}\right)$ in 2007 (Figure 11a). This is again linked to the thinning ice cover that leads to enhanced PAR and hence PP in ice-covered areas where nutrient drawdown is less severe than in the permanent ice-free areas (Figures 3 and 101-10n). In fact, the vertically integrated PP in the upper $100 \mathrm{~m}$ increases mainly in the permanently and seasonally ice-covered areas with decreasing ice thickness and increasing summer melt back in recent years, as illustrated by August fields in Figures $12 \mathrm{a}-12 \mathrm{~d}$. In the permanent ice-free areas such as part of the GIN seas and southern Barents Sea, there is no discernable trend, downward or upward, in the simulated PP 
Table 3. Minimum, Maximum, and Mean Values of ModelSimulated Annual Pelagic Primary Productivity for Arctic Shelves, the North Pole Area, and the Greenland Sea Over 1988-2007 in Comparison With Observation Derived Values ${ }^{\mathrm{a}}$

\begin{tabular}{lll}
\hline \multicolumn{1}{c}{ Shelves $^{\mathrm{b}}$} & \multicolumn{1}{c}{ Modeled } & \multicolumn{1}{c}{ Observed } \\
\hline Barents & $41-87(65)$ & $20-200$ \\
Kara & $37-87(63)$ & $30-50$ \\
Laptev & $39-103(69)$ & $25-40$ \\
East Siberian & $38-110(72)$ & $25-40$ \\
Chukchi & $58-114(92)$ & 20 to $>400$ \\
Beaufort & $22-90(52)$ & $30-70$ \\
North Pole area & $1-12(7)$ & $15^{\mathrm{c}}$ \\
Greenland Sea & $75-109(91)$ & $81^{\mathrm{d}}$ \\
\hline
\end{tabular}

\footnotetext{
${ }^{\mathrm{a}}$ Mean values are given in parentheses.

${ }^{\mathrm{b}}$ Observation-derived values for Arctic shelves are from Carmack et al. [2006] [also see Sakshaug, 2004].

${ }^{\mathrm{c}}$ Total annual PP (phytoplankton plus ice algae) estimated by Gosselin et al. [1997] based on observations in the central Arctic.

${ }^{\mathrm{d}}$ Estimate for the open Greenland Sea from Richardson et al. [2005].
}

(Figures 12a-12d). This is also basically true with the surface concentration of chl $a$ biomass as shown in Figure 13 that displays both simulated and observed August fields for recent years.

[41] Nutrient limitation may have a significant role in the lack of a significant trend in the simulated PP in the permanent ice-free areas of the Barents and GIN seas. In summer, the simulated surface nitrate concentrations are very low in these regions (Figures 10k-10o), leading to often rather small PP (Figures 12e-12h) even with high PAR (Figure 3). As a result, the simulated PP often peaks at subsurface depths of $30-36 \mathrm{~m}$ in the Barents and GIN seas (Figures $12 \mathrm{~m}-12 \mathrm{p}$ ). Although to a lesser degree, nutrient drawdown also occurs in late summer in some of the permanently and seasonally ice-covered areas, according to the model (Figures 101-10n). As a result, the simulated surface PP in some of the Chukchi and Beaufort seas is also very small (Figures $12 \mathrm{e}-12 \mathrm{~h}$ ), and the subsurface PP maximum often occurs at the 20-25 m depth (Figures 12i-121), which generally agrees with the SBI observations (Figure 8).

[42] Overall, the simulated total PP (mean PP per unit area) in all areas combined of the Arctic Ocean increased from $456 \mathrm{Tg} \mathrm{Cyr}^{-1}\left(36 \mathrm{~g} \mathrm{C} \mathrm{m}^{-2} \mathrm{yr}^{-1}\right)$ in 1988 to $682 \mathrm{Tg} \mathrm{C} \mathrm{yr}^{-1}$ $\left(53 \mathrm{~g} \mathrm{C} \mathrm{m}^{-2} \mathrm{yr}^{-1}\right)$ in 2007. The simulated PP increases not only at the surface but also at various subsurface depths (Figure 11b). As PP increases, the simulated annual mean total biomass of phytoplankton (flagellates and diatoms) and zooplankton (microzooplankton, mesozooplankton, and predatory zooplankton) of the Arctic Ocean increases, from an annual mean total phytoplankton (zooplankton) biomass of 6.6 (8.9) Tg C in 1988 to 9.3 (11) Tg C in 2007 (Figures 11c11d). Again, because of the nutrient limitation, the increase in the simulated standing stocks of phytoplankton and zooplankton mainly occurs in the permanently and seasonally ice-covered areas, not necessarily in the permanent open water areas (Figure 14). For example, in some open water areas in the Greenland and Barents seas, the simulated biomass concentrations of flagellates, diatoms, microzooplankton, and mesozooplankton are not necessarily higher in 2007 than in 2004 (Figure 14), even though the total plankton biomass in the whole Arctic Ocean is higher in 2007 (Figure 11). In the
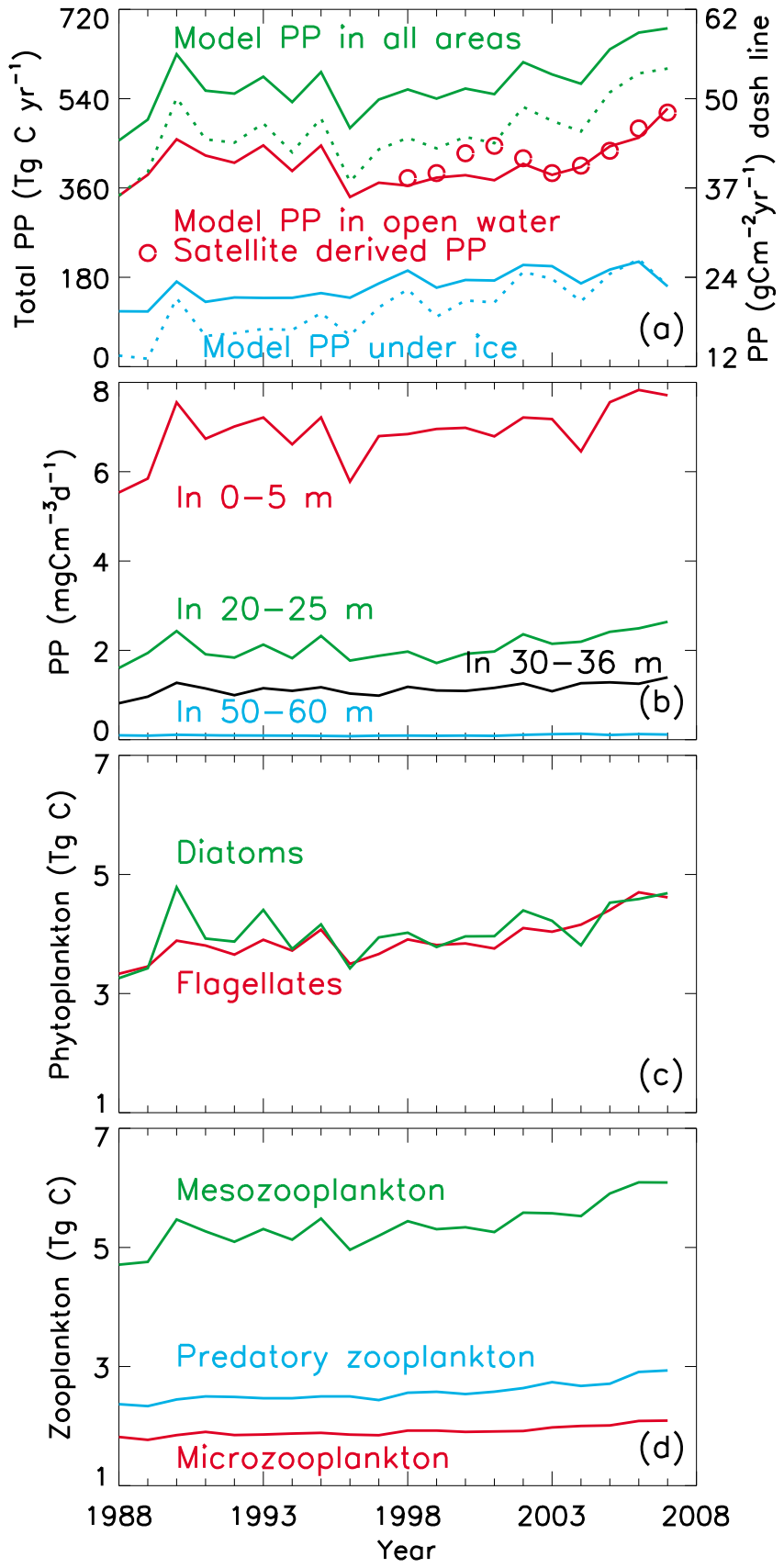

Figure 11. (a) Model-simulated (solid line) and satelliteobserved (circle) annual marine total PP and model-simulated annual marine mean PP per unit area (dash line), (b) modelsimulated annual mean PP per unit volume in different layers of the Arctic Ocean, and model-simulated annual mean biomasses of (c) phytoplankton and (d) zooplankton in the upper $100 \mathrm{~m}$ of the Arctic Ocean. In Figure 11a, the total PP is integrated over open water, ice-covered, and all (open water plus ice-covered) areas, the PP per unit area is averaged over ice-covered and all areas, and the biomasses of phytoplankton and zooplankton are integrated over all areas; the satellite observations of PP are derived by Pabi et al. [2008] and Arrigo et al. [2008] using SeaWiFS surface chl $a$ mainly in open-water areas. 

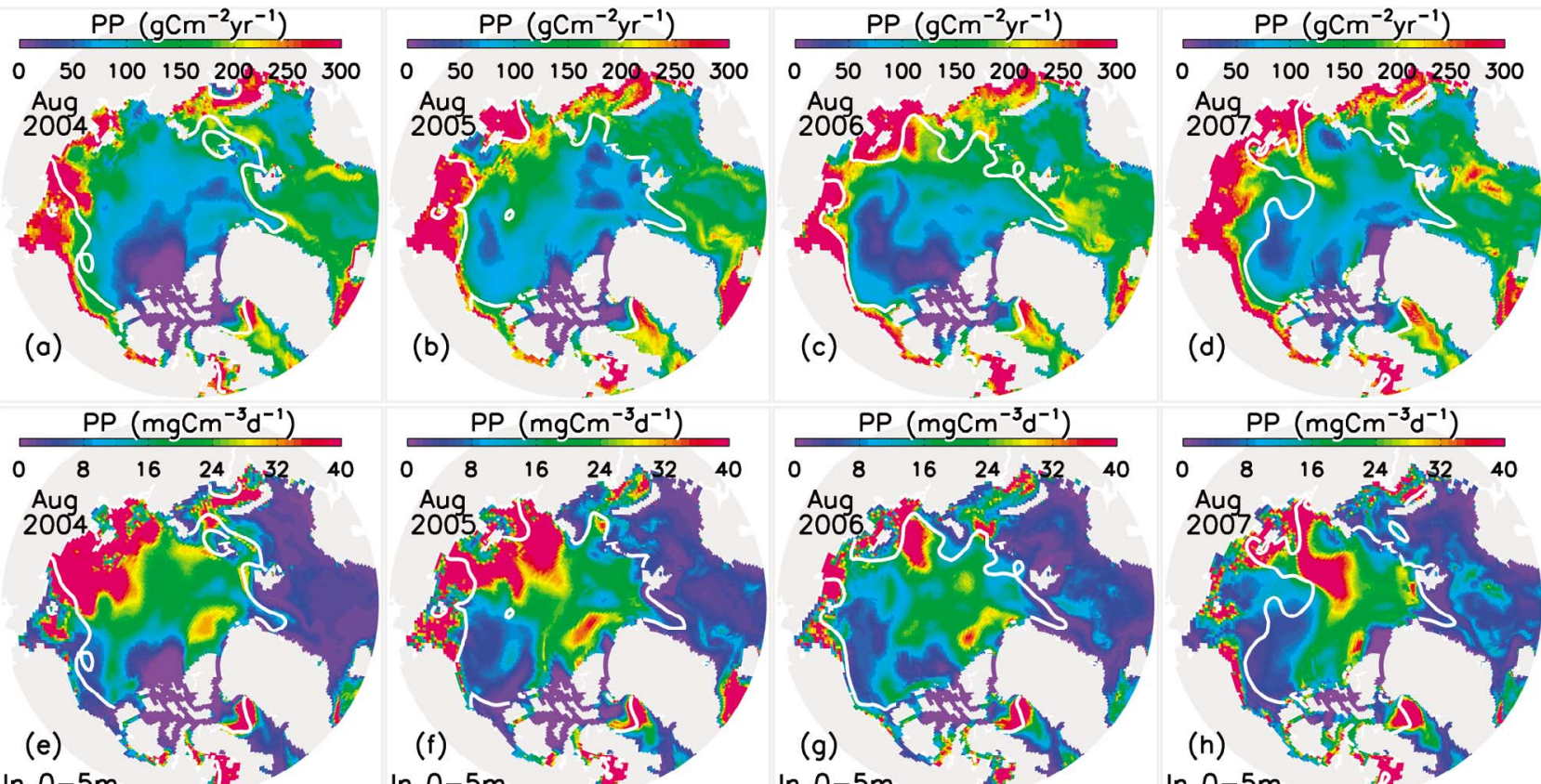

In $0-5 \mathrm{~m}$

In $0-5 m$

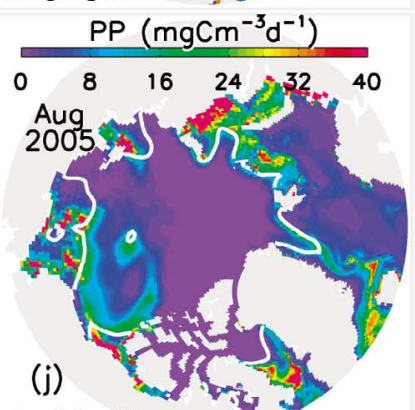

In 20-25m,
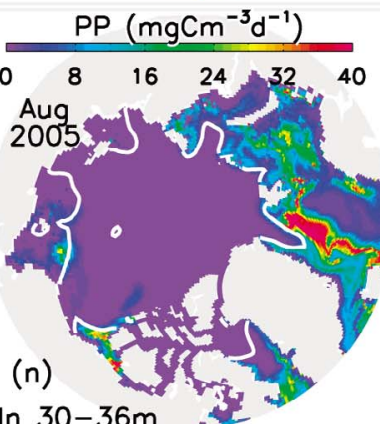

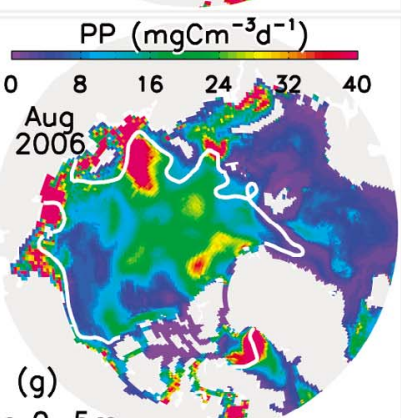

In $0-5 m$

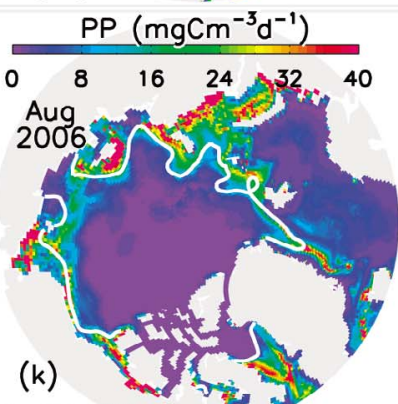

In $20-25 m$
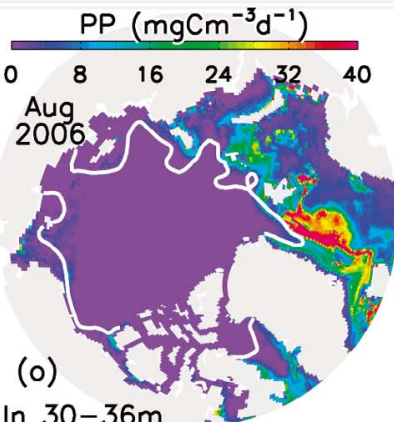

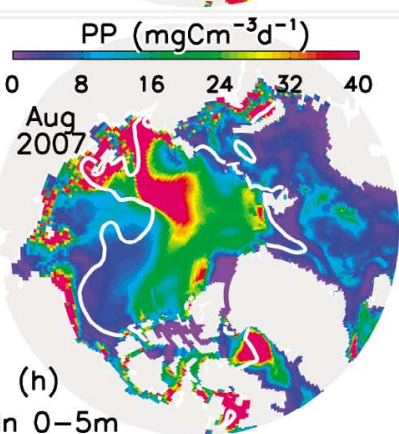

In $0-5 m$

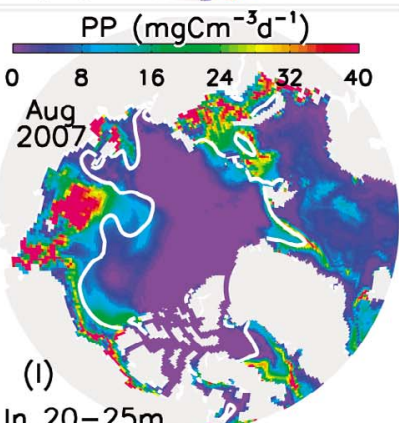

In $20-25 m \& 2$

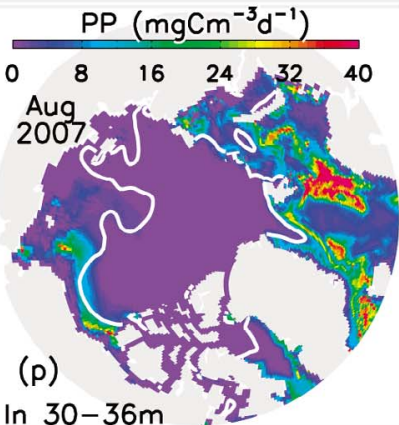

Figure 12. Simulated $P P$ vertically integrated in the $(\mathrm{a}-\mathrm{d})$ upper $100 \mathrm{~m}$ and simulated PP per unit volume in the (e-h) 0-5 m, (i-l) 20-25 m, and (m-p) 30-36 m ocean layers for August of 2004 through 2007. The white line represents simulated ice edge.

permanently ice-covered central Arctic where light limitation dominates, an increase in PAR generally results in an increase in biomass, according to the model (Figures 3, 12, 13, and 14).

[43] The model simulated flagellates are generally more abundant than the simulated diatoms in the Barents and GIN seas (Figure 14). However, diatoms often dominate the primary production on most of the Arctic shelves in agreement with observations [Booth and Horner, 1997; Gosselin et al., 1997]. The model also shows that copepods dominate the total zooplankton biomass in essentially all areas of the Arctic Ocean in agreement with observations [e.g., Thibault et al., 1999; Arashkevich et al., 2002; Ashjian et al., 2003; Campbell et al., 2009].

[44] The seasonal changes in PP and plankton biomass in response to seasonal changes in sea ice conditions are illustrated in Figure 15. The dramatic summer ice retreat in 2007 and the steady decrease in ice thickness in recent years are reflected in Figures $15 \mathrm{a}-15 \mathrm{~b}$, and the consequently increased summer PAR is reflected in Figure 15c. The simulated sea- 

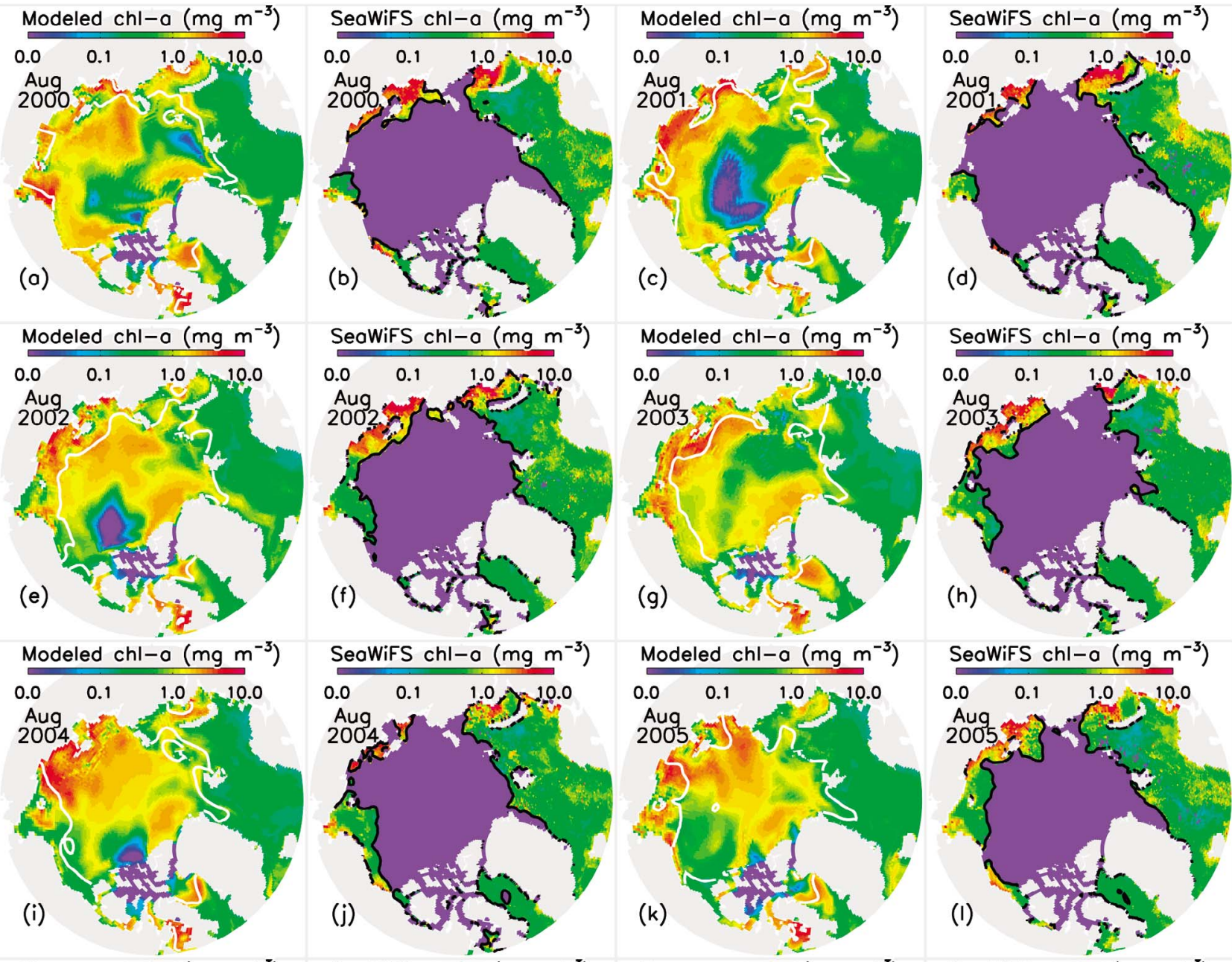

Modeled $\mathrm{chl}-\mathrm{o}\left(\mathrm{mg} \mathrm{m}^{-3}\right)$
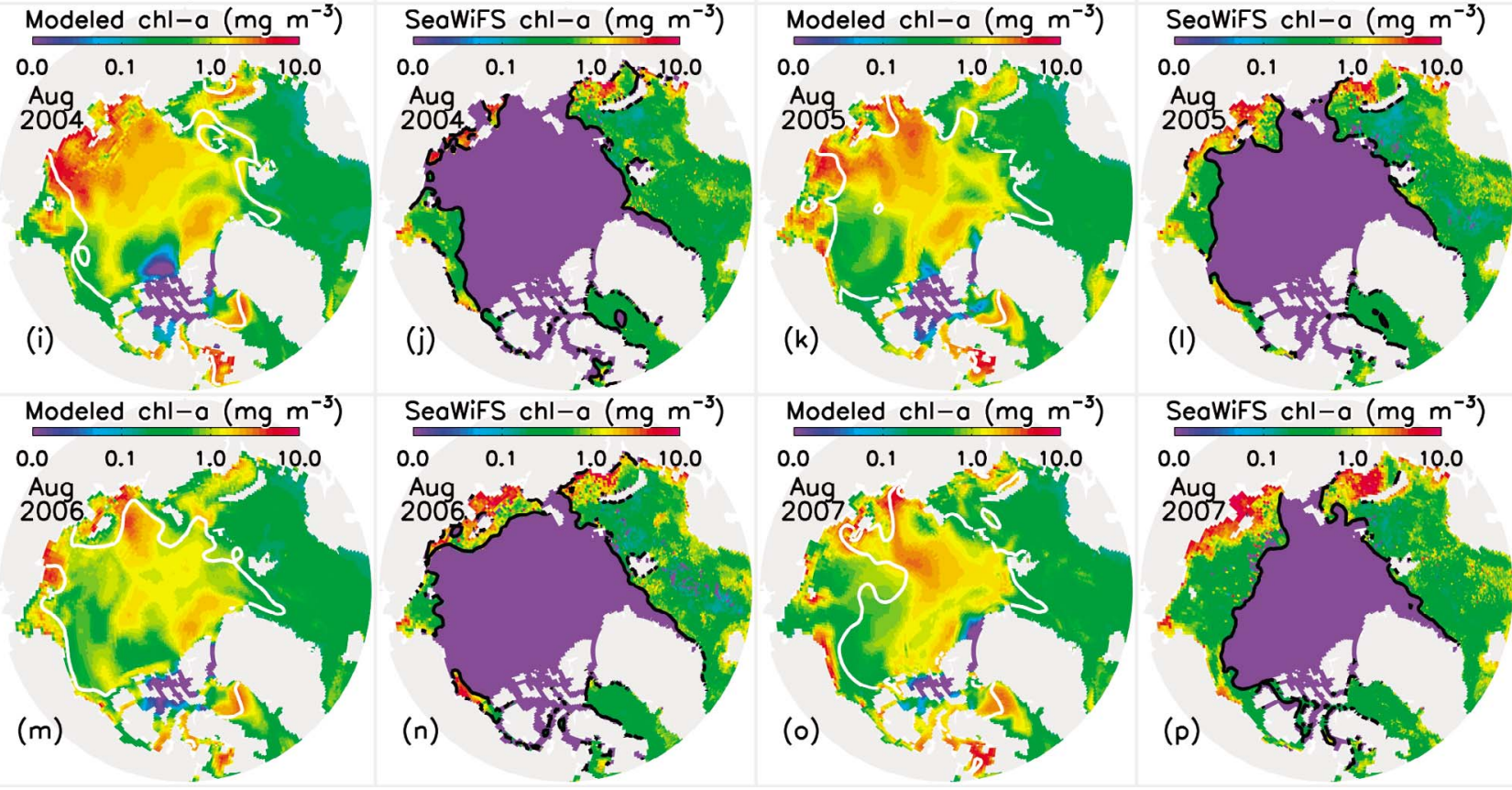

Figure 13. Model-simulated monthly mean and SeaWiFS-observed monthly composite surface concentration of chl $a$ for August of 2000 through 2007. The white line represents model-simulated ice edge, and black line indicates satellite-observed ice edge. SeaWiFS chl $a$ under ice is not plotted.

sonal variations of the total PP over the entire Arctic Ocean for 2004 through 2006 (Figure 15d) closely resemble those shown in Figure 7d of the study of Pabi et al. [2008]. However, the simulated values are higher than the Pabi et al. [2008] SeaWiFS-derived values because the former include the ice-covered areas of the central Arctic. The simulated total PP and total biomass of flagellates and diatoms generally peak in either July or August (Figures 15d-15f). However, there is a smaller peak in diatom biomass in May. The seasonal cycle of the simulated total biomass of micro- zooplankton is of one peak in August (Figure 15g), whereas the biomass of mesozooplankton often reaches its maximum in September followed by a peak in the biomass of predatory zooplankton in October (Figures 15h-15i). It is clear that as sea ice declines in summer, biological productivity and the standing stocks of plankton species all increase to a varying degree, according to the model. Despite the dramatic decreases in observed ice extent and earlier sea ice retreat in 2007, that year did not show consistent differences, over the whole Arctic Ocean, in the timing or magnitude of simulated bio- 

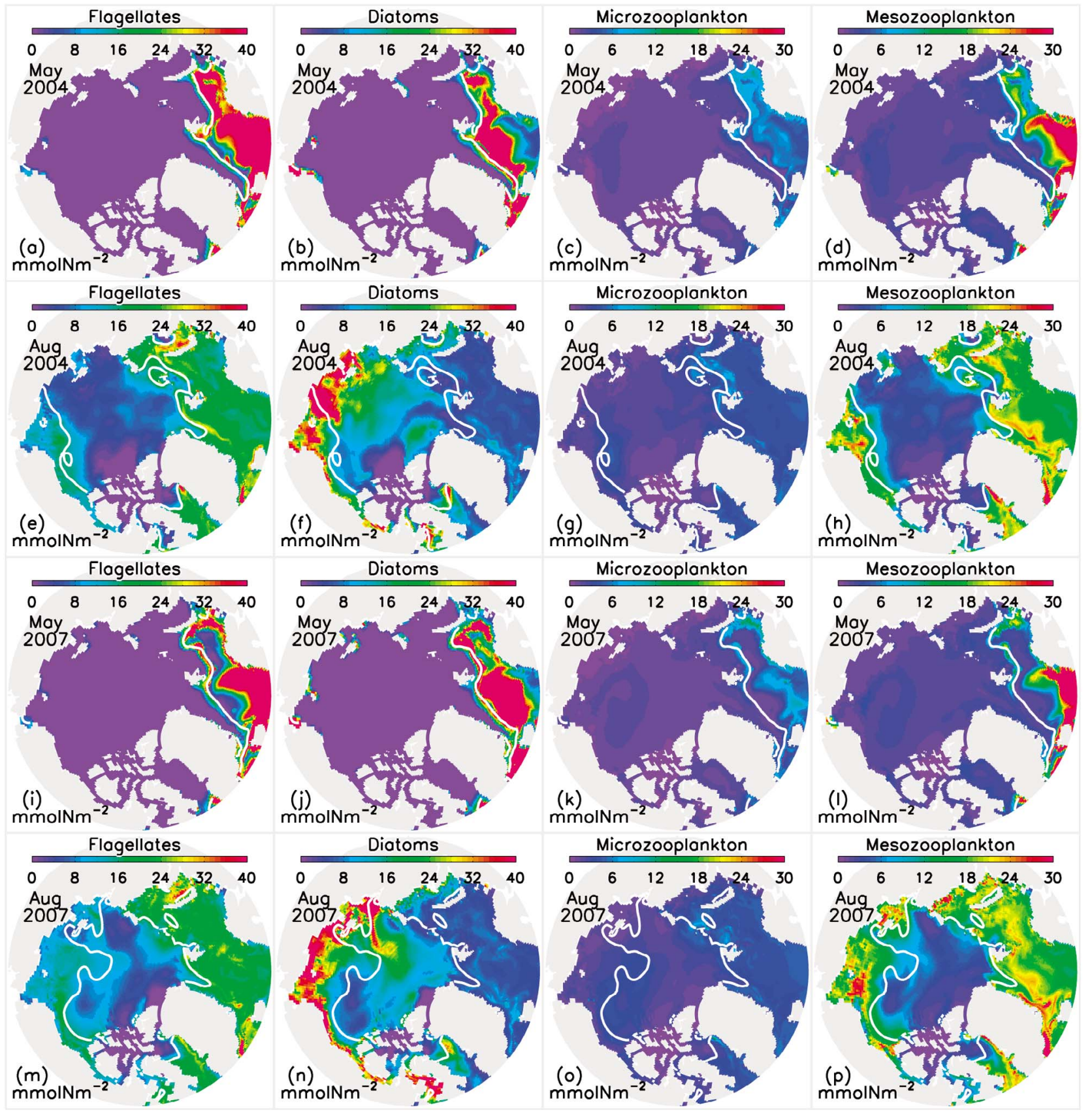

Figure 14. Simulated mean biomass concentration of flagellates, diatoms, microzooplankton, mesozooplankton/copepods in the upper $100 \mathrm{~m}$ for May and August of 2004 and 2007. The white line represents simulated ice edge.

logical variables relative to those of the previous 3 years (Figure 15).

\section{Conclusions}

[45] We have developed a coupled 3-D pan-Arctic biology/ sea ice/ocean model to investigate the impact of declining sea ice on the marine planktonic ecosystem in the Arctic Ocean over the past two decades. While there are many uncertainties in model parameterization, forcing, and initialization, owing to limited observations of arctic biological processes, the coupled biophysical model is able to basically capture the timing of the spring bloom in the open water area of the Greenland Sea and the seasonally ice-covered area of the Chukchi/Beaufort seas, compared with in situ observations. The simulated PP and chl $a$ and plankton biomass in these two areas are generally within the range of available in situ and satellite observations, with underestimation or overestimation from time to time and from location to location (Figures 5 and 7). The simulated mean PP values averaged for various Arctic shelves, the North Pole area, and the Greenland Sea over 1988-2007 are generally comparable with the in situ observations [Carmack et al., 2006; Sakshaug, 2004; Gosselin et al., 1997; Richardson et al., 2005]. Par- 

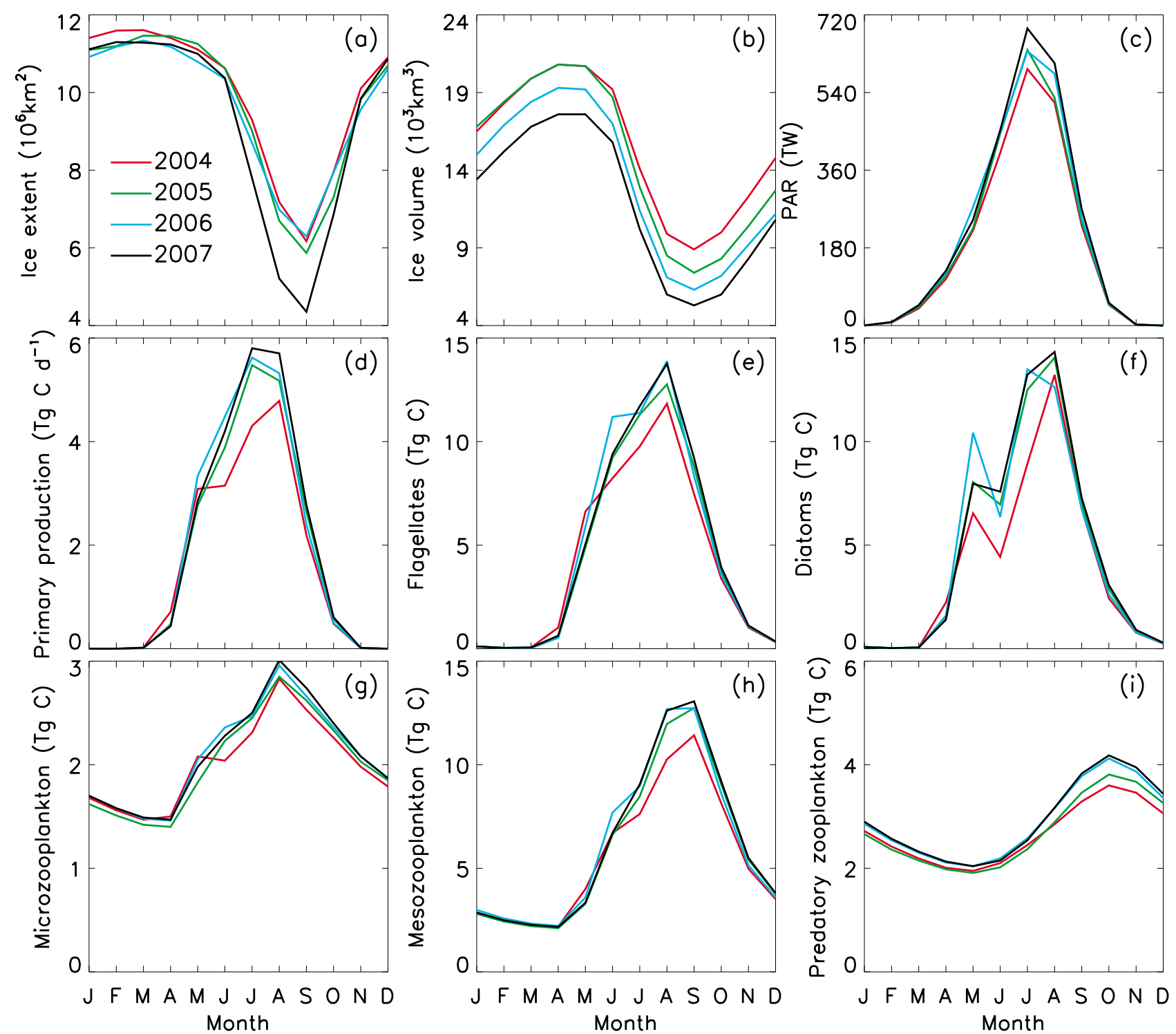

Figure 15. (a) Satellite-observed monthly mean sea ice extent; model-simulated (b) monthly mean sea ice volume and (c) total surface PAR in the Arctic Ocean; model-simulated (d) total primary production and (e) biomass of flagellates, (f) diatoms, (g) microzooplankton, (h) mesozooplankton, and (i) predatory zooplankton in the upper $100 \mathrm{~m}$ over both open water and ice-covered areas of the Arctic Ocean.

ticularly, the simulated annual total PP in open water areas of the Arctic Ocean is in close agreement with that derived by Pabi et al. [2008] and Arrigo et al. [2008] using SeaWiFS surface chl $a$ mainly in open water areas.

[46] Model deficiencies do exist. The model underestimates the timing of primary production bloom and zooplankton biomass in the permanently ice-covered area of the Canadian Basin along the SHEBA track, owing likely to model overestimation (underestimation) of snow depth (PAR) and to uncertainties in model parameters such as phytoplankton photoinhibition and photochemical reaction coefficients and zooplankton grazing and mortality rates. The underestimation of zooplankton biomass may also suggest the importance of incorporating sea ice algae in the model for ice-covered areas where ice algae may have a significant role in primary production [Gosselin et al., 1997]. In addition, seasonal vertical migration of mesozooplankton contribute substantially to changes in biomass in surface waters of the central Arctic Ocean [Ashjian et al., 2003; Olli et al., 2007], and this is not included in the model. The model may also underestimate summer chl $a$ in some coastal areas near the mouth of major rivers. This stresses the necessity of incorporating into the model the input of nutrients from runoff of large rivers.

[47] The simulated planktonic ecosystem at the SBI locations in the Chukchi/Beaufort seas with a seasonal ice cover is subject to considerably more spatial and temporal variability than in the open water area of the Greenland Sea and in the permanently ice-covered area of the Canadian Basin. There are more fluctuations in the timing of spring bloom and the magnitude of PP and plankton biomass throughout spring, summer, and even early fall. This is because the 
changes in ice/snow thickness in the seasonally ice-covered region cause more variations in PAR by modifying surface albedo and light penetration through sea ice.

[48] The simulated ice extent and thickness agree reasonably well with satellite and submarine observations, which allows for quantifying the increase in PAR in both open water and ice-covered areas as a result of significant warming in the Arctic in recent years. Both model results and satellite observations show a generally downward trend in summer ice extent over 1988-2007. As a result, the simulated annual mean total surface PAR in open water areas of the Arctic Ocean has increased, from 104 TW in 1988 to 150 TW in 2007 with record low summer ice extent. The simulated ice thickness has decreased steadily over 1988-2007 in most of the Arctic Ocean. As a result, the total PAR (mean PAR per unit area) in ice-covered areas of the Arctic Ocean has increased, from $42 \mathrm{TW}\left(4.7 \mathrm{Wm}^{-2}\right)$ in 1988 to $59 \mathrm{TW}$ $\left(8.0 \mathrm{Wm}^{-2}\right)$ in 2007 . Overall, the simulated total PAR (mean PAR per unit area) in all areas of the Arctic Ocean has increased from $146 \mathrm{TW}\left(11.4 \mathrm{Wm}^{-2}\right)$ in 1988 to $209 \mathrm{TW}$ $\left(16.3 \mathrm{Wm}^{-2}\right)$ in 2007 , an increase of $43 \%$. The increase in PAR mainly occurs in the seasonally and permanently icecovered Arctic Ocean.

[49] The decline of sea ice also affects nutrient availability in the euphotic zone of the Arctic Ocean during 1988-2007 by changing the air-sea momentum transfer at the ocean surface. Being thinner with less coverage, sea ice in recent years tends to enhance air-sea momentum transfer at the surface, leading to a general increase in the magnitude of surface ocean stress and the curl of surface ocean stress during 1988-2007. An increase in surface ocean stress and stress curl tends to enhance circulation, upwelling, and mixing in the water column, which leads to an increase in the nitrate input into the upper $100 \mathrm{~m}$ and $50 \mathrm{~m}$. The role of nutrients in the arctic marine biological processes is reflected in the fact that the simulated marine PP is highly positively correlated with the nitrate input into the euphotic zone but is highly negatively correlated with the summer nitrate concentration in the upper $50 \mathrm{~m}$. The effect of nutrient limitation is further reflected in the fact that, because of nitrate drawdown, the simulated summer surface PP is small in various parts of the Arctic Ocean such that a subsurface PP peak often forms. Particularly, the simulated or observed subsurface chl $a$ and PP maxima at three SBI sites are in conjunction with surface nitrate depletion.

[50] The combined increase in PAR and nutrient supply into the euphotic zone results in an increase in marine PP, mainly, again, in the seasonally and permanently ice-covered Arctic Ocean during 1988-2007, especially since 1996. There is no significant trend with the simulated PP in the permanent ice-free areas where nutrient limitation dominates. The simulated annual total PP (mean PP per unit area) in the upper $100 \mathrm{~m}$ in open water areas of the Arctic Ocean has increased, from $344 \mathrm{Tg} \mathrm{C} \mathrm{yr}^{-1}\left(105 \mathrm{~g} \mathrm{C} \mathrm{m}^{-2} \mathrm{yr}^{-1}\right)$ in 1988 to $520 \mathrm{Tg} \mathrm{C} \mathrm{yr}^{-1}\left(120 \mathrm{~g} \mathrm{C} \mathrm{m}^{-2} \mathrm{yr}^{-1}\right)$ in 2007 . This agrees generally with the studies by Pabi et al. [2008] and Arrigo et al. [2008] that report an increasing trend in PP in open water areas over 1998-2007. However, this study shows that the simulated total PP (mean PP per unit area) has generally increased over 1988-2007 in ice-covered areas of the Arctic

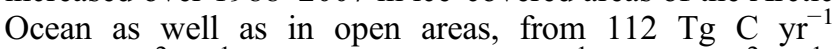
(14 $\left.\mathrm{g} \mathrm{C} \mathrm{m}^{-2} \mathrm{yr}^{-1}\right)$ in 1988 to $162 \mathrm{Tg} \mathrm{C} \mathrm{yr}^{-1}\left(23 \mathrm{~g} \mathrm{C} \mathrm{m}^{-2} \mathrm{yr}^{-1}\right)$ in 2007. Overall, the simulated total PP (mean PP per

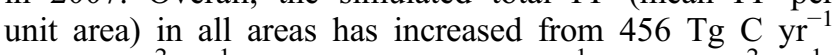
(36 $\left.\mathrm{g} \mathrm{C} \mathrm{m}^{-2} \mathrm{yr}^{-1}\right)$ in 1988 to $682 \mathrm{Tg} \mathrm{C} \mathrm{yr}^{-1}\left(53 \mathrm{~g} \mathrm{C} \mathrm{m}^{-2} \mathrm{yr}^{-1}\right)$ in 2007 , an increase of $50 \%$.

[51] Surface waters in the Arctic Ocean have warmed in association with increasing surface absorption of solar energy and rising surface air temperature. The model simulates an average increase of $0.5^{\circ} \mathrm{C}$ in the water temperature of the whole upper Arctic Ocean from 1988 to 2007. Such an increase is mainly due to the significant warming of the surface waters in the Arctic Ocean peripheral seas [Steele et al., 2008], which also contributes to the PP increase. As the total PP has increased, the simulated annual mean total biomass of phytoplankton (zooplankton) in the Arctic Ocean has increased from 6.6 (8.9) $\mathrm{Tg} \mathrm{C}$ in 1988 to 9.3 (11) $\mathrm{Tg} \mathrm{C}$ in 2007 , an increase of $41 \%(24 \%)$. The increase in zooplankton biomass is due to the increase in phytoplankton concentration as well as water temperature.

[52] Further refinement of the model is necessary to address the model deficiencies mentioned above, including more accurate simulation of snow depth and ice thickness, improved open boundary conditions, incorporation of ice algae and river input of nutrients, representation of ontogenetic migration of mesozooplankton in the Arctic basin, and improved parameterization of the grazing terms that at present are not completely accurate. These changes should improve modeldata comparisons in the Arctic basin and coastal areas. The discrepancies between modeled and observed results, particularly those at the SHEBA sites with permanent ice coverage, also emphasizes the need for continued observation of the Arctic biological and physical system to better define parameters that will be used in models such as organism vital rates and distributions, light penetration through snow covered ice, and seasonal cycles in biological and chemical components.

\section{Appendix A: Changes in Kishi et al. [2007] Model Equations}

[53] Some of the Kishi et al. [2007] model equations are modified to take into account microzooplankton (ZS) grazing on diatoms (PD). Only those modified equations with newly added terms are listed here. All the other equations and terms are described in detail in Appendix A of Kishi et al. [2007] and not repeated here. Definitions of parameters can be found in Table 1 as well as in the study by Kishi et al. [2007]. In the listed equations, physical terms of diffusion and advection and suffixes $n$ and si, used by Kishi et al. to distinguish nitrogen and silicon flows, are not included for simplicity. To be consistent with the symbols in the study by Kishi et al., here we keep the notations of PL and PS. Note, however, that PL and PS have been redefined in this model to represent diatoms (PD) and flagellates (PF), respectively.

\section{A1. Nitrogen}

[54]

$$
\begin{aligned}
\mathrm{dPL} / \mathrm{dt}= & \mathrm{GppPL}-\text { ResPL }- \text { MorPL }- \text { ExcPL }- \text { GraPL2ZS } \\
& - \text { GraPL2ZL }- \text { GraPL2ZP } \\
\mathrm{dZS} / \mathrm{dt}= & \text { GraPS2ZS }+ \text { GraPL2ZS }- \text { GraZS2ZL } \\
& - \text { GraZS2ZP }- \text { MorZS }- \text { ExcZS }- \text { EgeZS }
\end{aligned}
$$


In the above equations,

ExcZS $=($ AlphaZS - BetaZS $)($ GraPS2ZS + GraPL2ZS $)$ and

EgeZS $=(1-$ AlphaZS $)($ GraPS2ZS + GraPL2ZS $)$.

GraPL2ZS is grazing rate of diatoms by microzooplankton such that

$$
\begin{aligned}
\text { GraPL2ZS }= & \operatorname{Max}\left[0, \mathrm{GR}_{\operatorname{maxSpl}} \exp \left(k_{\mathrm{GraS}} \times \mathrm{TMP}\right)\right. \\
& \left.\cdot\left(1-\exp \left(\lambda_{S}(\mathrm{PL} 2 \mathrm{ZS} *-\mathrm{PL})\right)\right) \mathrm{ZS}\right]
\end{aligned}
$$

where TMP is water temperature.

\section{A2. Silicon}

$\mathrm{dOpal} / \mathrm{dt}=$ MorPL + EgeZS + EgeZL + EgeZP - SED - DecP2,

where the added new term EgeZS is egestion rate of microzooplankton.

[56] Acknowledgments. We thank E. Sherr for assistance in analyzing SBI observations and B. Tremblay and three anonymous reviewers for their constructive comments. We gratefully acknowledge the support of NSF (grants ARC-0629326, ARC-0629312, ARC-0629348, ARC-0629495, and $\mathrm{ARC}-0805789$ ).

\section{References}

Andersen, O. G. N. (1989), Primary production, chlorophyll, light, and nutrients beneath the Arctic sea ice, in The Arctic Seas, edited by Y. Herman, 147-191, Von Nostrand Reinhold.

Arashkevich, E., P. Wassmann, A. Pasternak, and C. Wexels Riser (2002), Seasonal and spatial changes in biomass, structure, and development progress of the zooplankton community in the Barents Sea, J. Mar. Syst., $38(1-2), 125-145$.

Arrigo, K. R., J. N. Kremer, and C. W. Sullivan (1993), A simulated Antarctic fast-ice ecosystem, J. Geophys. Res., 98(C4), 6929-6946, doi:10.1029/ 93JC00141.

Arrigo, K. R., D. L. Worthen, and D. H. Robinson (2003), A coupled ocean-ecosystem model of the Ross Sea: 2. Iron regulation of phytoplankton taxonomic variability and primary production, J. Geophys. Res., 108(C7), 3231, doi:10.1029/2001JC000856.

Arrigo, K. R., G. van Dijken, and S. Pabi (2008), Impact of a shrinking Arctic ice cover on marine primary production, Geophys. Res. Lett., 35, L19603, doi:10.1029/2008GL035028.

Ashjian, C. J., R. G. Campbell, H. E. Welch, M. Butler, and D. Van Keuren (2003), Annual cycle in abundance, distribution, and size in relation to hydrography of important copepod species in the western Arctic Ocean, Deep Sea Res., Part I, 50, 1235-1261.

Aumont, O., E. Maier-Reimer, S. Blain, and P. Pondaven (2003), An ecosystem model of the global ocean including $\mathrm{Fe}, \mathrm{Si}, \mathrm{P}$ colimitations, Global Biogeochem. Cycles, 17(2), 1060, doi:10.1029/2001GB001745.

Belchansky, G. I., D. C. Douglas, and N. G. Platonov (2004), Duration of the Arctic Sea ice melt season: Regional and interannual variability, 1979-2001, J. Clim., 17(1), 67-80.

Bluhm, B. A., and R. Gradinger (2008), Regional variability in food availability for Arctic marine mammals, Ecol. Appl., 18, 577-596.

Booth, B. C., and R. A. Horner (1997), Microalgae on the Arctic Ocean Section, 1994: Species abundance and biomass, Deep Sea Res., Part II, 44, 1607-1622.

Bryan, K. (1969), A numerical method for the study of the circulation of the world oceans, J. Comput. Phys., 4, 347-376.

Bunker, A. J., and A. G. Hirst (2004), Fecundity of marine planktonic copepods: Global rates and patterns in relation to chlorophyll a, temperature and body weight, Mar. Ecol. Prog. Ser., 279, 161-181.

Campbell, R. G., E. B. Sherr, C. J. Ashjian, S. Plourde, B. F. Sherr, V. Hill, and D. A. Stockwell (2009), Mesozooplankton prey preference and grazing impact in the western Arctic Ocean, Deep Sea Res., Part II, 56, 1274-1289.

Carmack, E., and P. Wassmann (2006), Food webs and physical-biological coupling on pan-Arctic shelves: Unifying concepts and comprehensive perspectives, Prog. Oceanogr., 71, 446-477.
Carmack, E. C., D. Barber, J. Christensen, R. Macdonald, B. Rudel, and E. Sakshaug (2006), Climate variability and physical forcing of the food webs and the carbon budget on pan-arctic shelves, Prog. Oceanogr., 71(2-4), 145-181.

Codispoti, L. A., C. Flagg, V. Kelly, and J. H. Swift (2005), Hydrographic conditions during the 2002 SBI process experiments, Deep Sea Res. Part II, 52, 3199-3226.

Codispoti, L. A., C. Flagg, and J. H. Swift (2009), Hydrographic conditions during the 2004 SBI process experiments, Deep Sea Res., Part II, 56 , 1144-1169.

Comiso, J. C., C. L. Parkinson, R. Gersten, and L. Sock (2008), Accelerated decline in the Arctic sea ice cover, Geophys. Res. Lett., 35, L01703, doi:10.1029/2007GL031972.

Cota, G. F., et al. (1996), Nutrients, primary production and microbial heterotrophy in the southeastern Chukchi Sea: Arctic summer nutrient depletion and heterotrophy, Mar. Ecol. Prog. Ser., 135, 247-258.

Cota, G. F., J. Wang, and J. Comiso (2004), Transformation of global satellite chlorophyll retrievals with a regionally tuned algorithm, Remote Sens. Environ., 90, 373-377.

Cox, M. D. (1984), A primitive equation, three-dimensional model of the oceans, GFDL Ocean Group Tech. Rep. No. 1, Geophys. Fluid Dynamics Lab./NOAA, Princeton Univ., Princeton, N.J.

Cushing, D. H. (1959), On the nature of production in the sea, Fish. Invest. Lond., Ser. B, 22(6), 40.

D'Asaro, E. A., and J. H. Morison (1992), Internal waves and mixing in the Arctic Ocean, Deep Sea Res., 39, suppl. 2, S459-S484.

Dukowicz, J. K., and R. D. Smith (1994), Implicit free-surface method for the Bryan-Cox-Semtner ocean model, J. Geophys. Res., 99, 7791-8014, doi:10.1029/93JC03455.

Ellingsen, I. H., P. Dalpadado, D. Slagstad, and H. Loeng (2008), Impact of climatic change on the biological production in the Barents Sea, Clim. Change, 87, 155-175.

Fennel, K., M. R. Abbott, Y. H. Spitz, J. G. Richman, and D. M. Nelson (2003), Modeling controls of phytoplankton production in the southwest Pacific sector of the Southern Ocean, Deep Sea Res., Part II, 50, 769-798.

Garcia, H. E., R. A. Locarnini, T. P. Boyer, and J. I. Antonov (2006), World Ocean Atlas 2005, vol. 4, Nutrients (phosphate, nitrate, silicate), edited S. Levitus, 396 pp., NOAA Atlas NESDIS 64, U.S. Govt. Printing Office, Washington, D. C.

Geider, R. J., H. L. MacIntyre, and T. M. Kana (1997), Dynamic model of phytoplankton growth and acclimation: responses of the balanced growth rate and the chlorophyll a: Carbon ratio to light, nutrient-limitation and temperature, Mar. Ecol. Prog. Ser., 148, 187-200.

Gosselin, M., M. Levasseur, P. E. Wheeler, R. A. Horner, and B. C. Booth (1997), New measurements of phytoplankton and ice algal production in the Arctic Ocean, Deep Sea Res., Part II, 44, 1623-1644.

Grebmeier, J. M., and J. P. Barry (1991), The influence of oceanographic processes on pelagic-benthic coupling in polar regions: A benthic perspective, J. Mar. Syst., 2, 495-518.

Grebmeier, J. M., and H. R. Harvey (2005), The Western Arctic ShelfBasin Interactions (SBI) project: An overview, Deep Sea Res., Part II, 52, 3109-3115.

Grenfell, T. C., and G. A. Maykut (1977), The optical properties of ice and snow in the Arctic Basin, J. Glaciol., 18, 445-463.

Hannon, E., P. W. Boyd, M. Silvoso, and C. Lancelot (2001), Modeling the bloom evolution and carbon flows during SOIREE: Implications for future in situ iron-enrichments in the southern Ocean, Deep Sea Res., Part II, 48, 2745-2773.

Hassol, S. J. (2004), Impacts of a Warming Arctic: Arctic Climate Impact Assessment, 139 pp., Cambridge Univ. Press, New York.

Hibler, W. D., III (1979), A dynamic thermodynamic sea ice model, J. Phys. Oceanogr., 9, 815-846.

Hibler, W. D., III (1980), Modeling a variable thickness sea ice cover, Mon. Weather Rev., 108, 1943-1973.

Hibler, W. D., III, and K. Bryan (1987), A diagnostic ice-ocean model, J. Phys. Oceanogr., 7, 987-1015.

Hill, V., and G. Cota (2005), Spatial patterns of primary production on the shelf, slope and basin of the Western Arctic in 2002, Deep Sea Res., Part II, 52, 3344-3354.

Hirst, A. G., and A. J. Bunker (2003), Growth of marine planktonic copepods: Global rates and patterns in relation to chlorophyll a, temperature, and body weight, Limnol. Oceanogr., 48, 1988-2010.

Huntley, M. E., and M. D. G. Lopez (1992), Temperature-dependent production of marine copepods: A global synthesis, Am. Nat., 140, 201-242.

Jin, M., C. J. Deal, J. Wang, K. H. Shin, N. Tanaka, T. E. Whitledge, S. H. Lee, and R. R. Gradinger (2006), Controls of the landfast ice-ocean ecosystem offshore Barrow, Alaska, Ann. Glaciol., 44, 63-72.

Kalnay, E., et al. (1996), The NCEP/NCAR 40-year reanalysis project, Bull. Am. Meteorol. Soc., 77, 437-471. 
Kerr, R. A. (2007), Is battered arctic sea ice down for the count?, Science, 318

Kishi, M. J. M., et al. (2007), NEMURO_-A lower trophic level model for the North Pacific marine ecosystem, Ecol. Model., 202, 12-25.

Kwok, R. (2007), Near-zero replenishment of the Arctic multiyear sea ice cover at the end of 2005 summer, Geophys. Res. Lett., 34, L05501, doi:10.1029/2006GL028737.

Lancelot, C., E. Hannon, S. Becquevort, C. Veth, and H. J. W. de Baar (2000), Modeling phytoplankton blooms and carbon export production in the Southern Ocean: Dominant controls by light and iron of the Atlantic sector in Austral spring 1992, Deep Sea Res., Part I, 47, 1621-1662.

Large, W. G., J. C. McWilliams, and S. C. Doney (1994), Oceanic vertical mixing: A review and a model with a nonlocal boundary layer parameterization, Rev. Geophys., 32, 363-403.

Lavoie, D., R.W. Macdonald, and K.L. Denman (2009), Primary productivity and export fluxes on the Canadian shelf of the Beaufort Sea: A modeling study, J. Mar. Syst., 75, 17-32.

Laxon, S., N. Peacock, and D. Smith (2003), High interannual variability of sea ice thickness in the Arctic region, Nature, 425, 947-950.

Lebedeva, L. P., E. A. Shushkina, and M. E. Vinogradov (1995), A dynamic model of the pelagic ecosystem of the Kara Sea, Oceanology, 34

Lee, S. H., and T. E. Whitledge (2005), Primary and new production in the deep Canada Basin during summer 2002, Polar Biol., 28, 190-197.

Lindsay, R. W., and J. Zhang (2005), The thinning of arctic sea ice, 19882003: Have we passed a tipping point?, J. Clim., 18, 4879-4894.

Lindsay, R. W., J. Zhang, A. Schweiger, M. Steele, and H. Stern (2009), Arctic sea ice retreat in 2007 follows thinning trend, J. Clim., 22, 165-176.

Maslanik, J. A., C. Fowler, J. Stroeve, S. D. Robot, J. Zwally, D. Yi, and W. Emery (2007), A younger, thinner Arctic ice cover: Increased potential for rapid, extensive sea-ice loss, Geophys. Res. Lett., 34, L24501, doi:10.1029/2007GL032043.

Matsuoka, A., Y. Huot, K. Shimada, S. Saitoh, and M. Babin (2007), Biooptical characteristics of the western Arctic Ocean: Implications for ocean color algorithms, Can. J. Remote Sens., 33, 503-518.

Maykut, G. A., and N. Untersteiner (1971), Some results from a timedependent thermodynamic model of sea ice, J. Geophys. Res., 76(06) 1550-1575, doi:10.1029/JC076i006p01550

Meier, W. N., J. Stroeve, and F. Fetterer (2007), Whither arctic sea ice? A clear signal of decline regionally, seasonally and extending beyond the satellite record, Ann. Glaciol., 46, 428-434.

Melnikov, I. A., E. G. Kolosova, H. E. Welch, and L. S. Zhitina (2002), Sea ice biological communities and nutrient dynamics in the Canadian Basin of the Arctic Ocean, Deep Sea Res., Part I, 49(9), 1623-1649.

Moline, M. A., N. J. Karnovsky, Z. Brown, G. J. Divoky, T. K. Frazer, C. A. Jacoby, J. J. Torres, and W. R. Fraser (2008), High-latitude changes in ice dynamics and their impact on polar marine ecosystems, Ann. N. Y. Acad. Sci., 1134(1), 267-319.

Møller, E. F., T. G. Nielsen, and K. Richardson (2006), The zooplankton community in the Greenland Sea: Composition and role in carbon turnover, Deep Sea Res., Part 1, 53, 76-93.

Mundy, C. J., et al. (2009), Contribution of under-ice primary production to an ice-edge upwelling phytoplankton bloom in the Canadian Beaufort Sea, Geophys. Res. Lett., 36, L17601, doi:10.1029/2009GL038837.

Nghiem, S. V., I. G. Rigor, D. K. Perovich, P. Clemente-Colon, and J. W. Weatherly (2007), Rapid reduction of Arctic perennial sea ice, Geophys. Res. Lett., 34, L19504, doi:10.1029/2007GL031138.

Olli, K., et al. (2007), The fate of production in the central Arctic OceanTop-down regulation by zooplankton expatriates?, Prog. Oceanogr., 72 84-113.

Pabi, S. K., G. L. van Dijken, and K. R. Arrigo (2008), Primary production in the Arctic Ocean, 1998-2006, J. Geophys. Res., 113, C08005, doi: $10.1029 / 2007 \mathrm{JC} 004578$.

Perovich, D. K., T. C. Grenfell, J. A. Richter-Menge, B. Light, W. B Tucker III, and H. Eicken (2003), Thin and thinner: Sea ice mass balance measurements during SHEBA, J. Geophys. Res., 108(C3), 8050 doi:10.1029/2001JC001079.

Perovich, D. K., B. Light, H. Eicken, K. F. Jones, K. Runciman, and S. V. Nghiem (2007), Increasing solar heating of the Arctic Ocean and adjacent seas, 1979-2005: Attribution and role in the ice-albedo feedback, Geophys. Res. Lett., 34, L19505, doi:10.1029/2007GL031480.

Perovich, D. K., J. A. Richter-Menge, and K. F. Jones (2008), Sunlight, water, and ice: Extreme Arctic sea ice melt during the summer of 2007, Geophys. Res. Lett., 35, L11501, doi:10.1029/2008GL034007.

Pinker, R. T., and I. Laszlo (1992), Global distribution of photosynthetically active radiation as observed from satellites, J. Clim., 5, 56-65.

Redfield, A. C., B. H. Ketchum, and F. A. Richards (1963), The influence of organisms on the composition of sea-water, in The Sea, edited by M. N. Hill, pp. 26-77, Wiley-Interscience, New York.
Reigstad, M., P. Wassmann, C. Wexels Riser, S. Oygarden, and F. Rey (2002), Variations in hydrography, nutrients and chlorophyll a in the marginal ice zone and the central Barents Sea, J. Mar. Syst., 38, 9-29.

Richardson, K., S. Markager, E. Buch, M. F. Lassen, and A. S. Kristensen (2005), Seasonal distribution of primary production phytoplankton biomass and size distribution in the Greenland Sea, Deep Sea Res., Part I, 52, 979-999.

Rothrock, D. A., Y. Yu, and G. A. Maykut (1999), Thinning of the arctic sea-ice cover, Geophys. Res. Lett., 26(23), 3469-3472, doi:10.1029/ 1999GL010863.

Rothrock, D. A., J. Zhang, and Y. Yu (2003), The Arctic ice thickness anomaly of the 1990s: A consistent view from models and observations, J. Geophys. Res., 108(C3), 3083, doi:10.1029/2001JC001208.

Rothrock, D. A., D. B. Percival, and M. Wensnahan (2008), The decline in arctic sea-ice thickness: Separating the spatial, annual, and interannual variability in a quarter century of submarine data, J. Geophys. Res., 113, C05003, doi:10.1029/2007JC004252

Sakshaug, E. (2004), Primary and secondary production in the Arctic seas, in The Organic Carbon Cycle in the Arctic Ocean, edited by R. Stein and R. W. Macdonald, pp. 57-82, Springer, Berlin.

Sakshaug, E., and D. Slagstad (1992), Sea ice and wind: Effects on primary productivity in the Barents Sea, Atmos. Ocean, 30, 579-591.

Sambrotto, R. N., H. J. Niebauer, J. J. Goering, and R. L. Iverson (1986), Relationships among vertical mixing, nitrate uptake, and phytoplankton growth during the spring bloom in the southwest Bering Sea middle shelf, Cont. Shelf Res., 5(1/2), 161-198.

Schmittner, A., A. Oschlies, X. Giraud, M. Eby, and H. L. Simmons (2005), A global model of the marine ecosystem for long-term simulations: Sensitivity to ocean mixing, buoyancy forcing, particle sinking, and dissolved organic matter cycling, Global Biogeochem. Cycles, 19 , GB3004, doi:10.1029/2004GB002283.

SEARCH SSC (2001), SEARCH: Study of Environmental Arctic Change, Science Plan, 89 pp., Polar Science Center, University of Washington, Seattle.

Semtner, A. J., Jr. (1986), Finite-difference formulation of a world ocean model, in Proc. NATO Advanced Physical Oceanographic Numerical Modeling, edited by J. O’Brien, 187-202, D. Riedel.

Serreze, M. C., M. M. Holland, and J. Stroeve (2007), Perspectives on the Arctic's shrinking sea-ice cover, Science, 315, 1533-1536.

Sherr, E. B., B. F. Sherr, P. A. Wheeler, and K. Thompson (2003), Temporal and spatial variation in stocks of autotrophic and heterotrophic microbes in the upper water column of the central Arctic Ocean, Deep Sea Res., Part I, 50, 557-571.

Sherr, E. B., B. F. Sherr, and A. J. Hartz (2009), Microzooplankton grazing impact in the Western Arctic Ocean, Deep Sea Res., Part II, 56, 1264-1273.

Slagstad, D., and K. Stole-Hansen (1991), Dynamics of plankton growth in the Barents Sea: Model studies, Polar Res., 10(1), 173-186.

Smith, R. D., J. K. Dukowicz, and R. C. Malone (1992), Parallel ocean general circulation modeling, Physica D, 60, 38-61.

Smith, W. O., and E. Sakshaug (1990), Polar phytoplankton, in Polar Oceanography, Part B, edited by W. O. Smith, pp. 475-525, Academic, San Diego.

Steele, M., W. Ermold, and J. Zhang (2008), Arctic Ocean surface warming trends over the past 100 years, Geophys. Res. Lett., 35, L02614, doi:10.1029/2007GL031651.

Stroeve, J., T. Markus, W. N. Meier, and J. Miller (2006), Recent changes in the Arctic melt season, Ann. Glaciol., 44(1), 367-374.

Stroeve, J., et al. (2008), Arctic sea ice extent plummets in 2007, EOS Trans. $A G U, 89(2)$.

Thibault, D., E. J. H. Head, and P. A. Wheeler (1999), Mesozooplankton in the Arctic Ocean in summer, Deep-Sea Res., Part I, 46, 1391-1415.

Tremblay, J.-E., et al. (2008), Vertical stability and the annual dynamics of nutrients and chlorophyll fluorescence in the coastal, southeast Beaufort Sea, J. Geophys. Res., 113, C07S90, doi: 10.1029/2007JC004547.

Uttal, T., et al. (2002), The Surface Heat Budget of the Arctic Ocean (SHEBA), Bull. Am. Meteorol. Soc., 255- 275.

Walsh, J. J., and D. A. Dieterle (1994), $\mathrm{CO}_{2}$ cycling in the coastal ocean. I. A numerical analysis of the southeastern Bering Sea with applications to the Chukchi Sea and the northern Gulf of Mexico, Prog. Oceanogr., 34, 335-392.

Walsh, J. J., D. A. Dieterler, F. E. Muller-Karger, K. Aagaard, A. T. Roach T. E. Whitledge, and D. Stockwell (1997), $\mathrm{CO}_{2}$ cycling in the coastal ocean. II. Seasonal organic loading of the Canadian Basin from source waters of Bering Strait, Cont. Shelf Res., 17, 1-36.

Walsh, J. J., D. A. Dieterle, W. Maslowski, and T. E. Whitledge (2004), Decadal shifts in biophysical forcing of Arctic marine food webs: Numerical consequences, J. Geophys. Res., 109, C05031, doi:10.1029/ 2003JC001945. 
Walsh, J. J., et al. (2005), A numerical model of seasonal primary production within the Chukchi/Beaufort Seas, Deep Sea Res., Part II, 52, 3541-3576.

Wassmann, P., I. Andreassen, M. Reigstad, and D. Slagstad (1996), Pelagic-benthic coupling in the Nordic seas: The role of episodic events, Mar. Ecol., 17, 447-471.

Wassmann, P., D. Slagstad, M. Reigstad, and C. W. Riser (2006), Modeling the ecosystem dynamics of the Barents Sea including the marginal ice zone II. Carbon flux and interannual variability, J. Mar. Syst., 59, 1-24.

Wheeler, P. A. (1997), Preface: The Arctic Ocean Section, Deep Sea Res. Part II, 44, 1483-1485.

Wheeler, P. A., M. Gosselin, E. Sherr, D. Thibault, D. L. Kirchman, R. Benner, and T. Whitledge (1996), Active cycling of organic carbon in the central Arctic Ocean, Nature, 380, 697-699.

Wheeler, P. A., J. M. Watkins, and R. L. Hansing (1997), Nutrients, organic carbon and organic nitrogen in the upper water column of the Arctic Ocean: Implications for the sources of dissolved organic carbon, Deep Sea Res., Part II, 44(8), 1571-1592.

Zhang, J., and W. D. Hibler III (1997), On an efficient numerical method for modeling sea ice dynamics, J. Geophys. Res., 102(C4), 8691-8702, doi:10.1029/96JC03744.

Zhang, J., and D. A. Rothrock (2003), Modeling global sea ice with a thickness and enthalpy distribution model in generalized curvilinear coordinates, Mon. Weather. Rev., 131(5), 681-697.

Zhang, J., and D. A. Rothrock (2005), The effect of sea-ice rheology in numerical investigations of climate, J. Geophys. Res., 110, C08014, doi:10.1029/2004JC002599.

Zhang, J., and M. Steele (2007), The effect of vertical mixing on the Atlantic water layer circulation in the Arctic Ocean, J. Geophys. Res., 112, C04S04, doi:10.1029/2006JC003732.
Zhang, J., W. D. Hibler III, M. Steele, and D. A. Rothrock (1998), Arctic ice-ocean modeling with and without climate restoring, J. Phys. Oceanogr., 28, 191-217.

Zhang, J., D. A. Rothrock, and M. Steele (2000), Recent changes in Arctic Sea ice: The interplay between ice dynamics and thermodynamics, J. Clim., 13, 3099-3114.

Zhang, J., R. W. Lindsay, M. Steele, and A. Schweiger (2008), What drove the dramatic retreat of Arctic sea ice during summer 2007?, Geophys. Res. Lett., 35, L11505, doi:10.1029/2008GL034005.

C. Ashjian, Department of Biology, Woods Hole Oceanographic Institution, 266 Woods Hole Rd., Woods Hole, MA 02543, USA.

L. Berline, UPMC-University of Paris 6, UMR 7093, Laboratoire d'Océanographie de Villefranche, Observatoire Oceanographique F-06234, Villefranche-sur-Mer, France.

R. Campbell, Graduate School of Oceanography, University of Rhode Island, Narragansett, RI 02882, USA.

P. Matrai, Bigelow Laboratory for Ocean Sciences, 180 McKown Point Rd., West Boothbay Harbor, ME 04575, USA.

Y. H. Spitz, Oregon State University, College of Oceanic and Atmospheric Sciences, 104 COAS Administration Bldg., Corvallis, OR 97331-5503, USA.

M. Steele and J. Zhang, Applied Physics Laboratory, University of Washington, 1013 NE 40th St., Seattle, WA 98105-6698, USA. (zhang@apl.washington.edu) 